\title{
Reconstrucción virtual del exterior del complejo funerario de Sarenput I (QH36)
}

\author{
Virtual reconstruction of the outer section of the funeral complex \\ of Sarenput I (QH36)
}

\author{
Juan Antonio Martínez Hermoso ${ }^{1}$ \\ Proyecto Qubbet el-Hawa (Universidad de Jaén)
}

\begin{abstract}
RESUMEN
El complejo funerario de Sarenput I (QH36) destaca por ser el único de los construidos en la necrópolis de Qubbet el-Hawa, que fue completamente terminado. Además, destaca por ser uno de los escasos ejemplos de la arquitectura funeraria privada del Reino Medio, junto con las monumentales tumbas de Qaw el-Kebir y de Assiut que, de manera simplificada, sigue la estructura de los complejos funerarios reales con escalera ascendente, patio exterior, capilla funeraria y cámaras de enterramiento. En este artículo se aporta la reconstrucción gráfica "ideal" de los espacios exteriores de QH36, conservados parcialmente, basándonos en dos niveles de conocimiento: los elementos arquitectónicos y otras evidencias arqueológicas existentes en el recinto exterior que nos permiten su reconstrucción garantizando su autenticidad y la falta de algunos de éstos que nos obliga a tomar decisiones interpretativas que, basadas en el estudio de ejemplos de la arquitectura egipcia contemporánea, garanticen un modelo con rigurosidad y veracidad histórica.
\end{abstract}

Palabras clave: Arqueología; arquitectura funeraria; planimetría; Qubbet el-Hawa; Sarenput I.

\begin{abstract}
The funeral complex of Sarenput I (QH36) stands out as being the only one built in the necropolis of Qubbet el-Hawa, which was completely finished. In addition, it stands out as o ne of the few examples of the Middle Kingdom's private funerary architecture, along with the monumental tombs of Qaw el-Kebir and Asyut, which in a simplified way follows the structure of royal funerary complexes with ascending stair, outer court, funerary chapel and burial chambers. This paper contributes to the "ideal" graphic reconstruction of the outer spaces of QH36, preserved partially, based on two levels of knowledge: the architectural elements and other archaeological evidences existing in the outer enclosure allow us its reconstruction guaranteeing its accurary; on the other hand, the lack of some of these elements forces us to make interpretative decisions that, based on the study of examples from contemporary Egyptian architecture, guarantee a model with accuracy and historical rigurosity.
\end{abstract}

Key words: Archaeology; funerary architecture; planimetry; Qubbet el-Hawa; Sarenput I.

Recibido: 13-09-2017. Aceptado: 24-11-2017. Publicado online: 18-07-2018.

Cómo citar este artículo / Citation

Martínez Hermoso, J. A. 2018: "Reconstrucción virtual del exterior del complejo funerario de Sarenput I (QH36)", Arqueología de la Arquitectura, 15: e071. https://doi.org/10.3989/arq.arqt.2018.006

Copyright: (c) 2018 CSIC. Este es un artículo de acceso abierto distribuido bajo los términos de la licencia de uso y distribución Creative Commons Reconocimiento 4.0 Internacional (CC BY 4.0). 


\section{INTRODUCCIÓN}

Se conoce que el complejo funerario QH36 fue construido en la necrópolis de Qubbet el-Hawa durante el reinado de Senwosret I, ya que en una biografía de su propietario, Sarenput I, se hace mención a que el rey Kheperkara (Senwosret I) lo nombró gobernador de Elefantina (para la transcripción total del texto, ver De Morgan et al. 1894: 189-190; Gardiner 1908: lám. VII; Sethe 1935: Urk VII, 4-5).

Se trata del primero, y más antiguo, de un grupo de grandes complejos funerarios construidos en la necrópolis durante la Dinastía XII $\left(1939^{+16}-1760\right)^{2}$ que destacan por un cambio en el diseño arquitectónico y en el acabado final.

Uno de los motivos por los que fue construido en el extremo septentrional de la necrópolis (Fig. 1), probablemente fuera debido a la falta de espacio ya que, durante este período, localizar un lugar disponible era un condicionante importante al haberse excavado la mayor parte de los hipogeos, durante el Reino Antiguo y el Primer Período Intermedio (Martínez Hermoso 2015). En esta zona la pendiente es más suave lo que permitió la construcción de un gran patio delantero y una monumental fachada porticada.

De hecho, en la actualidad se considera que el exterior del complejo funerario QH36 es el único de la Dinastía XII, de Qubbet el-Hawa, que fue completamente terminado (Müller 1940: 16-17).

Además, destaca por ser uno de los escasos ejemplos conocidos de la arquitectura funeraria privada del Reino Medio, junto a las monumentales tumbas $\mathrm{n}^{\mathrm{o}} 7 \mathrm{y}$ 8 (de Wakha I e Ibu, del reinado de Senwosret II) y ${ }^{\circ}$ 18 (de Wakhka II, del reinado de Senwosret III) en Qaw el-Kebir (Steckeweh 1936: pls. II, IV, VI y VII), y a la tumba P.10.1 (de Djefaihapi I, del reinado de Senwosret I) en Assiut (El-Khadragy 2007: 41-6) que, de manera simplificada, cuentan con las mismas partes que los complejos funerarios reales del Reino Medio ${ }^{3}$ (a pesar de presentar estéticas o aspectos completamente distintos), con escalera ascendente, patio exterior, capilla funeraria y cámaras de enterramiento (Fig. 2).

\footnotetext{
Cronología extraída de Hornung, Krauss y Warburton 2006.

Los monumentos funerarios reales de este período son básicamente del tipo hipogeo bajo templo (el caso de Mentuhotep II en Deir el-Bahari) o de tipo pirámide exenta dentro de un complejo funerario con tumbas secundarias de tipo mastaba o piramidal menor de princesas, reinas y miembros de la élite o de la familia real (como el caso de los monarcas de principios de la Dinastía XII en Lisht, Dahshur, etc.).
}

\section{ESTADO ACTUAL}

\section{Escalera ascendente}

En las inmediaciones del complejo funerario QH36 se observa el tramo final de una escalera monumental que conduce directamente hasta la entrada de su patio exterior (Fig. 3).

La escalera tiene un ancho medio de entre 3.30-3.35 metros. Cada uno de sus peldaños está construido con dos losas de piedra arenisca, de diferentes tamaños, las mayores con dimensiones de entre 2.10-2.30 metros de largo, 0.50-0.60 metros de ancho y 0.15-0.20 metros de espesor. Se encuentra delimitada por pequeños muretes laterales, de unos 0.60 metros de espesor, de mampostería en seco construidos con los escombros producidos en las excavaciones antiguas, y que sirven como parapeto de protección contra la invasión de la arena.

Llama la atención que la escalera no fuera orientada según el eje principal del hipogeo, en este caso, orientado en la dirección cardinal intermedia SOE-NE, como era lo habitual en la necrópolis. Probablemente se debió a que en este caso se buscó reducir o aprovechar la pendiente natural del terreno y evitar complicaciones constructivas, aunque también a que ésta se dispuso siguiendo el camino más corto desde la puerta de entrada del patio del complejo funerario hasta el embarcadero existente en la orilla del Nilo, en las inmediaciones del arranque otras escaleras más antiguas situadas en esta vertiente de la colina (Martínez Hermoso 2017: 126-127).

\section{Patio exterior}

El patio exterior del complejo funerario QH36 era el espacio que servía como zona de transición entre el exterior del complejo y el interior del hipogeo.

$\mathrm{Su}$ frente delantero fue cerrado con un muro de mampostería construido con dos paramentos de aparejo irregular de bloques de piedra arenisca, encajados cuidadosamente unos con otros por su lado de unión, y labrados desde la parte superior hacia abajo, ligeramente ataludados, de los que sólo quedan la parte inferior (Müller 1940: 16-17), presentando en la actualidad un recrecido posterior realizado con piedras de menor tamaño colocadas en seco procedentes de escombros.

Las paredes laterales, cortadas directamente en la roca, con los bordes superiores siguiendo la línea de la pendiente de la ladera (Fig. 4), fueron posteriormente recrecidas, usando el mismo sistema constructivo que en el muro delantero hasta igualar su altura en todo su perímetro. 


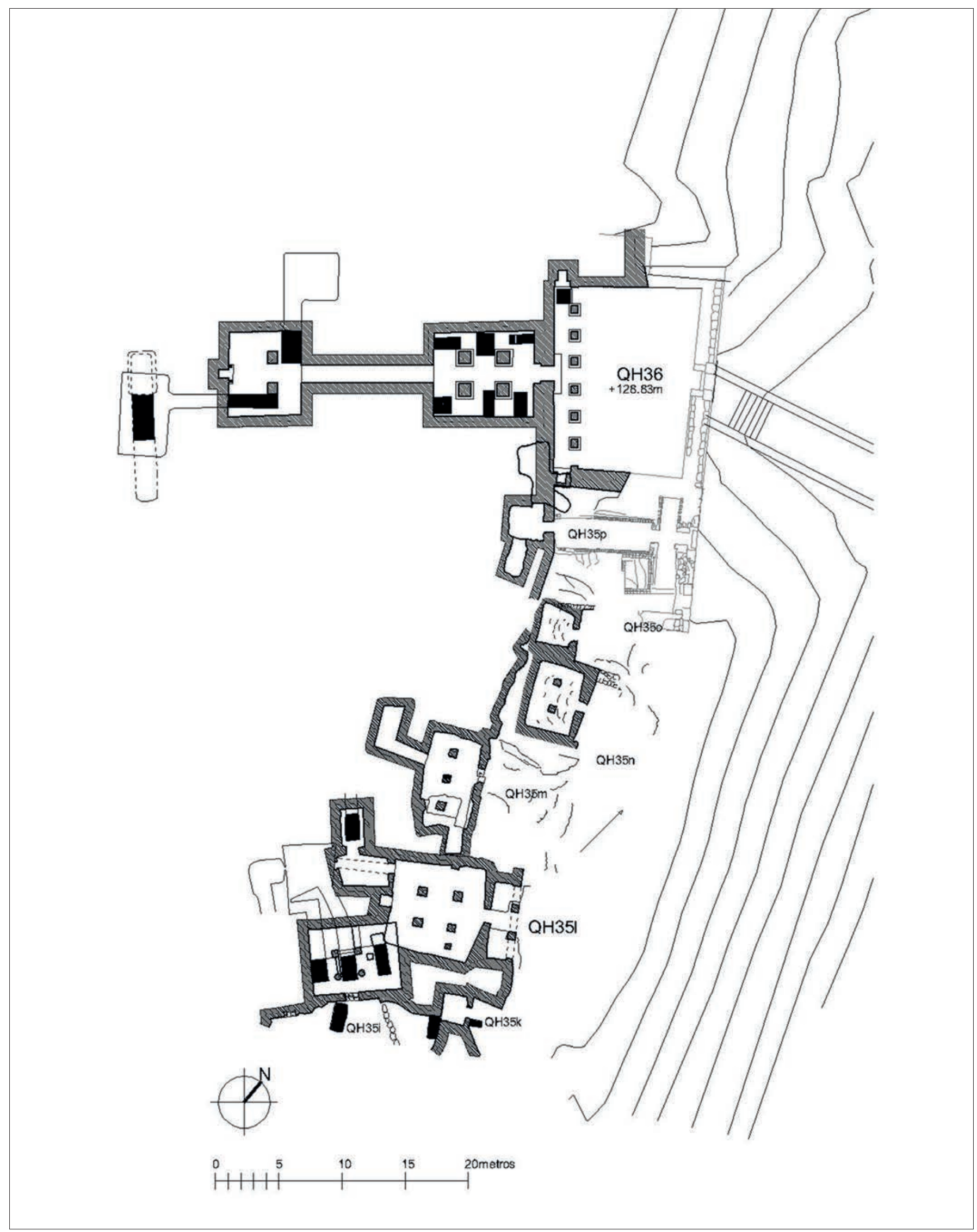

Figura 1. Plano de situación del complejo funerario de Sarenput I (QH36). 


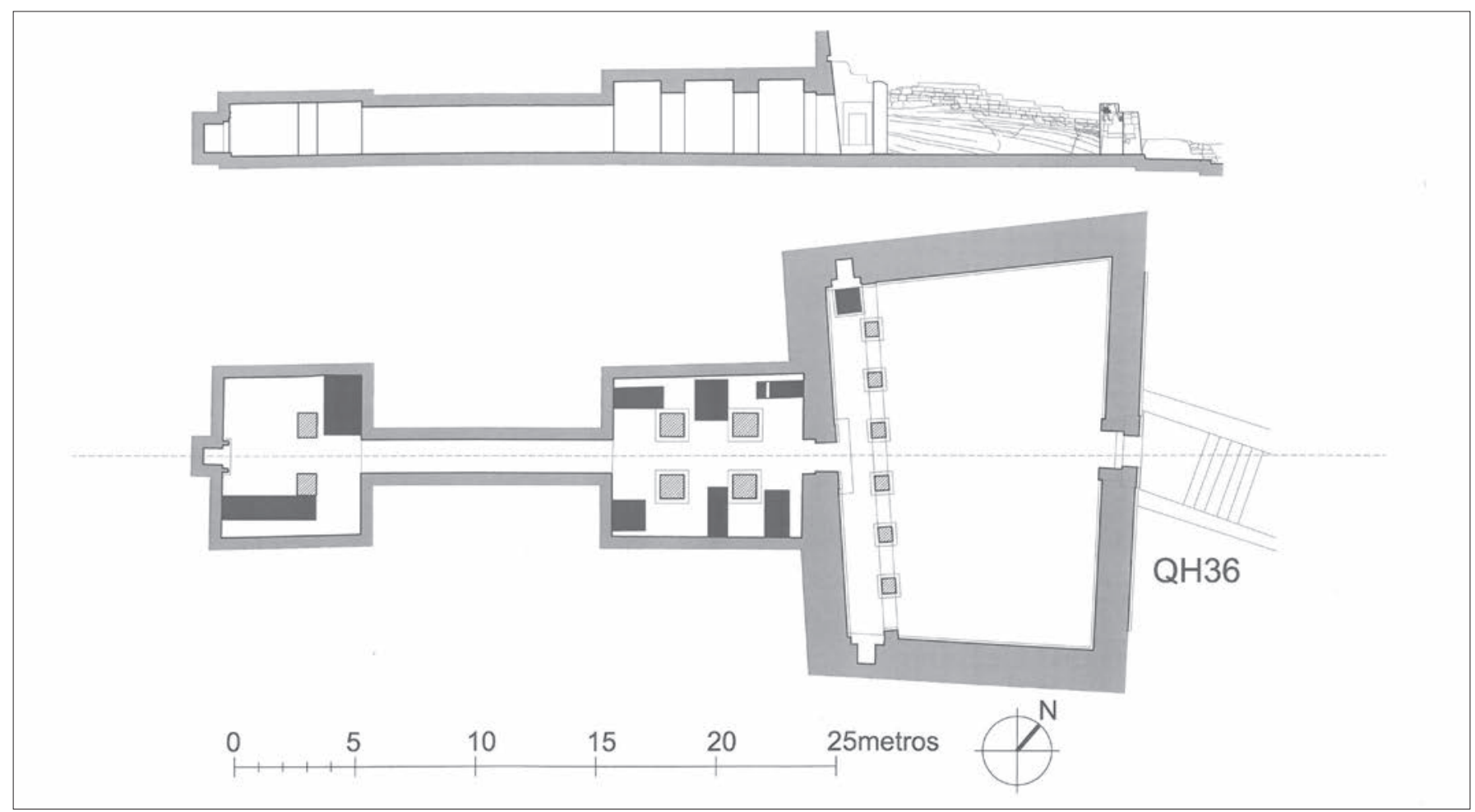

Figura 2. Planta y sección longitudinal del complejo funerario de Sarenput I (QH36).

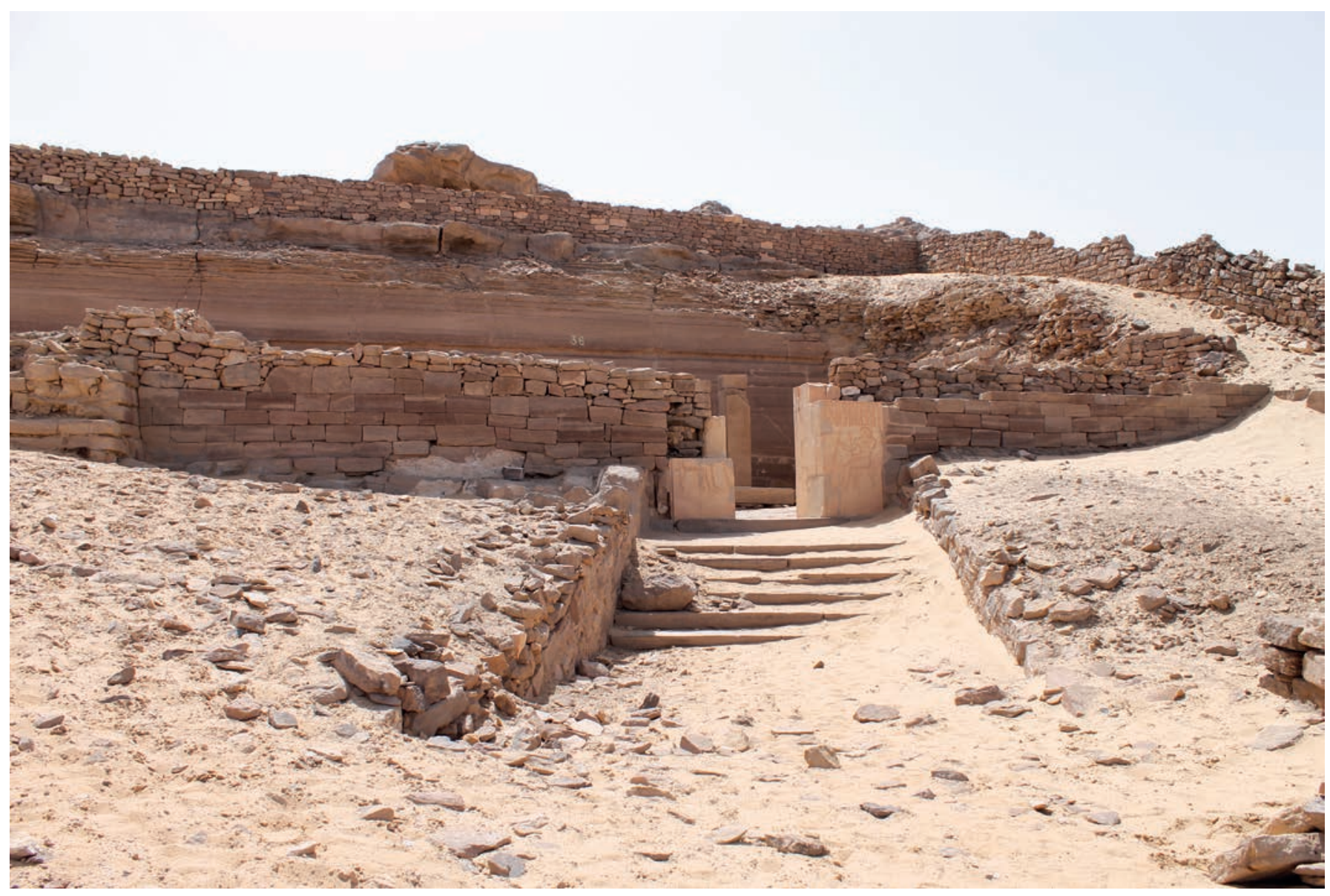

Figura 3. Vista del exterior del complejo funerario de Sarenput I (QH36). 


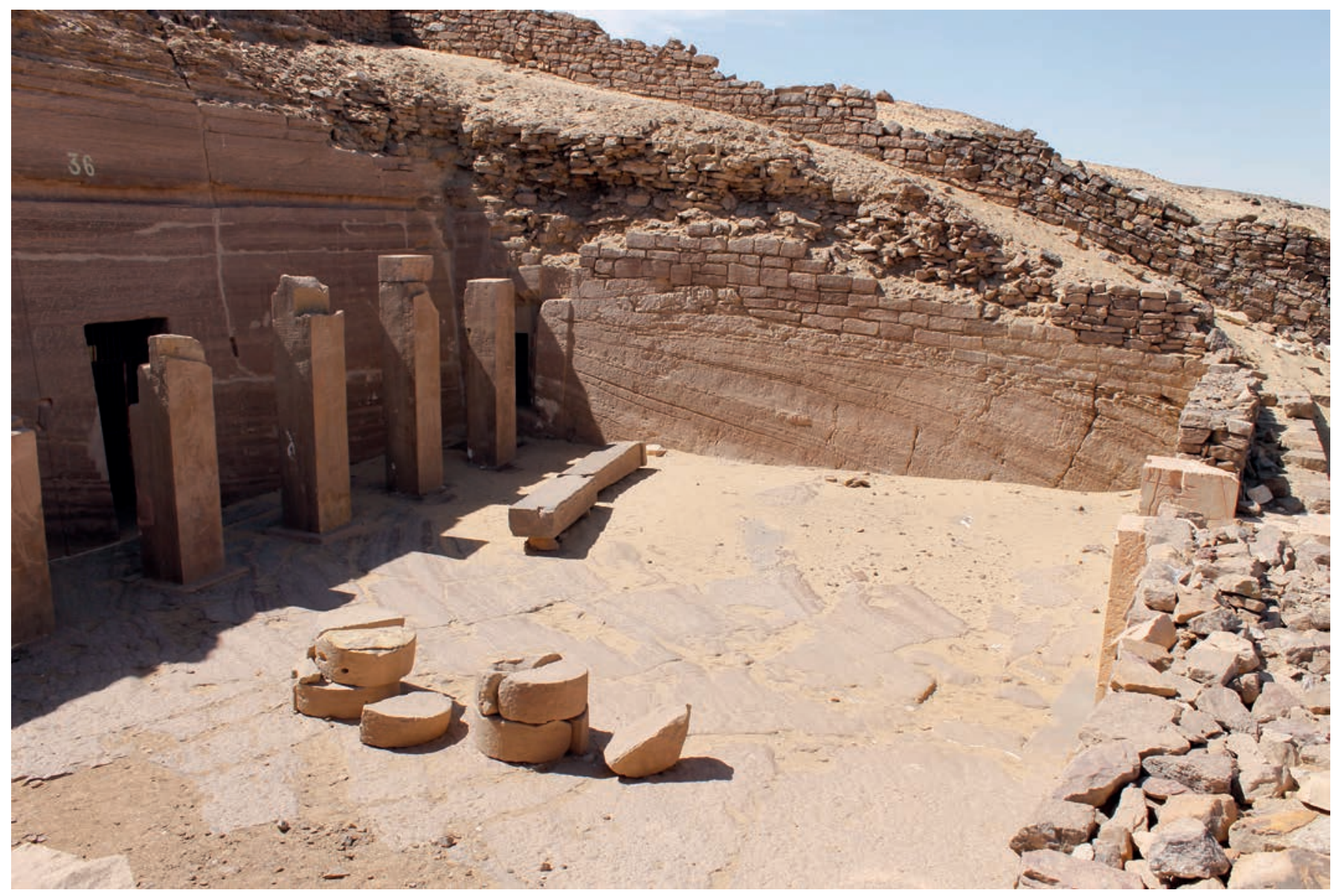

Figura 4. Mitad norte del patio exterior del complejo funerario de Sarenput I (QH36).

Probablemente los muros, al menos el muro delantero, fueron coronados con bloques tallados con forma semicircular, de los que todavía se conservan en la actualidad una decena de ellos apilados en el patio (Fig. 5), que colocados juntos equivalen a unos tres metros lineales de coronación de muro. Sus dimensiones difieren ligeramente debido a que, una vez situados los bloques toscos, se tallaban con la forma circular obteniendo una superficie continua y perfectamente lisa.

Pese a encontrarse parcialmente ocultos por la arena, en el exterior son visibles sus cimientos, que consisten en una o varias hiladas de bloques sin tallar pero perfectamente nivelados, colocados sobre la roca madre de la colina, sobresaliendo del plano perfectamente tallado de la cara exterior del muro (Fig. 6).

El patio exterior tiene forma trapezoidal. Las dimensiones de su perímetro interior son: en el muro de fachada del hipogeo (oeste), 14.68 metros; en la pared lateral norte, 11.80 metros; en el muro delantero del patio (este), 16.10 metros; y en la pared lateral sur, 10.20 metros.
No obstante, pese a su forma irregular, tanto la puerta de acceso al interior del hipogeo, como los pilares centrales del pórtico de fachada y la puerta del patio exterior están situadas sobre el eje central del hipogeo (ver Fig. 2), lo que permite a un observador situado en la puerta del patio tener la impresión de centralidad de la puerta y de uniformidad de vanos del pórtico.

\section{Puerta de acceso al patio}

La puerta de acceso al complejo funerario está situada, aproximadamente, en el centro del muro delantero del patio exterior (ver Fig. 3). Fue construida con bloques de piedra caliza siendo un caso excepcional en la necrópolis, ya que el material de construcción utilizado habitualmente en la necrópolis, para los elementos constructivos no excavados en la roca era la piedra arenisca, disponible en los alrededores.

Sin embargo, durante el Reino Medio otros monumentos funerarios en otras partes del país (Deir el-Bahari, El-Tarif, Saqqara, Lisht, Dahshur) sí que disfrutaron 


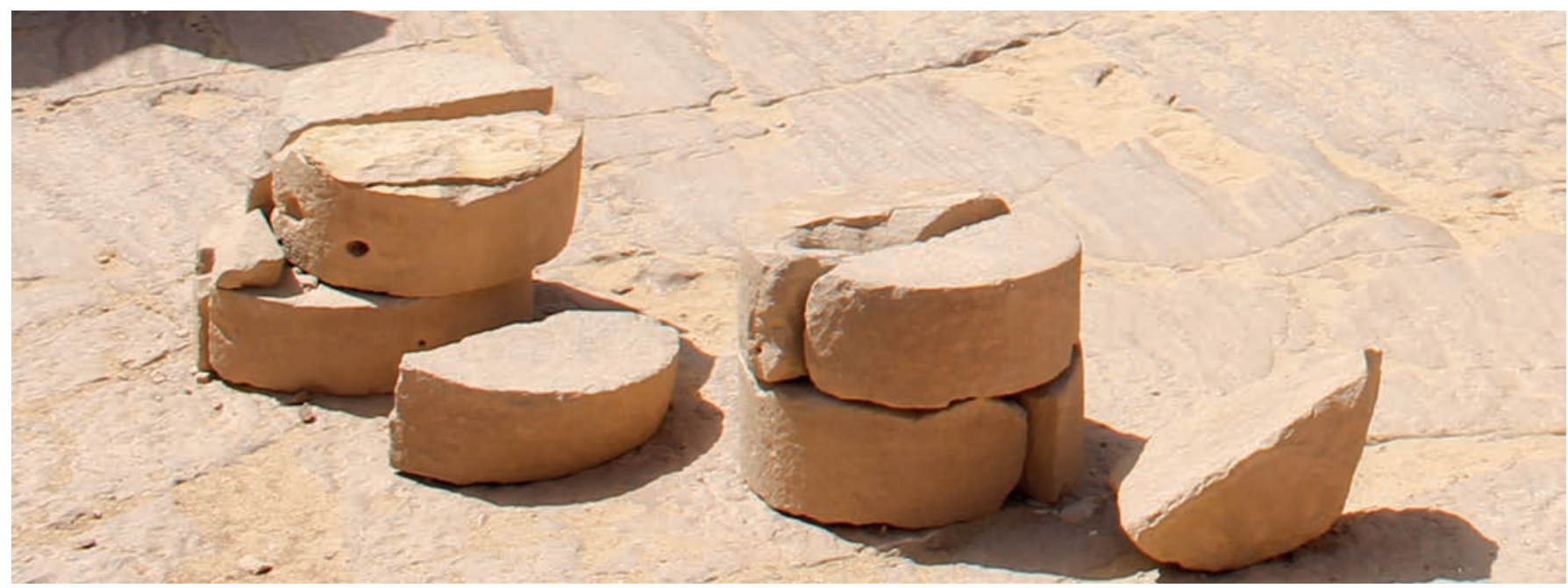

Figura 5. Bloques de coronación del muro del patio exterior de QH36.

de la presencia de caliza para la construcción de estos muros, pilares y columnas, así como revestimientos de cámaras, relegando, en algunos casos, el uso de bloques de arenisca a los suelos de los complejos.

Por ejemplo, la utilización de bloques de fina caliza como revestimiento de suelos y paredes es característica de los interiores de las tumbas privadas de la Dinastía XI, en Deir el-Bahari (Soliman 2009: 81-83). Entre estas tumbas destacan, en las laderas del acantilado norte de Deir el-Bahari, la tumba TT315 de Ipi (visir) (Winlock 1942: 54, fig. 6) y la tumba TT311 de Kheti (tesorero real) (Winlock 1942: 69, fig. 7); y en el sur, en Sheikh Abd el-Qurna, las tumbas TT103 de Dagi (visir) (Davies 1913: lámina 29), TT280 de Meket-re (tesorero, durante el reinado de Mentuhotep III) (Winlock 1955: 9-16 y 54) y TT60 de Senet (madre del visir Antefiker, durante los reinados de Amenemhet I y Senwosret I) (Davies y Gardiner 1920: lámina 1). Sin embargo, la mayor parte de estos bloques ya no se encuentran en su lugar al haber sido reutilizados como material de construcción para otras edificaciones. Por ejemplo, de la tumba TT 315 sólo quedan algunos bloques en el corredor descendente y en la cámara del sarcófago, habiendo desaparecido completamente el revestimiento de paredes y suelos de la cámara de culto, que ocultaba el acceso al corredor descendente, de la tapa del sarcófago que servía de suelo de la cámara subterránea, y del corredor horizontal de acceso al hipogeo (Soliman 2009: 117).

Probablemente, la utilización de caliza en el complejo funerario de Sarenput I esté relacionada con la reconstrucción en piedra caliza del templo de Satis en Elefantina, llevada a cabo durante el mismo período (en el reinado de Senwosret I), un pequeño templo construido de ladrillos de adobe durante el Reino Antiguo que había sido remodelado anteriormente manteniendo su forma básica durante el reinado de Mentuhotep III (Kaiser 1988: 152-157).

El marco exterior de la puerta (Fig. 7) estaba formado por un dintel que apoyaba sobre dos pilares, construidos con bloques de piedra caliza, separados entre sí 1.27 metros, de los que sólo quedan actualmente los restos de su parte inferior (1.43-1.63 metros de altura), habiéndose consolidado las discontinuidades existentes mediante el sellado con mortero de arena y cal. El recercado exterior, de 0.85 metros de ancho, tiene la misma inclinación que la cara exterior del muro donde está situado, pero sobresale ligeramente del plano del mismo. Éste fue decorado, simétricamente, con cuatro columnas de inscripciones jeroglíficas, de las que sólo se conservan parcialmente las del lado norte, que finalizan con sendas figuras sedentes del propietario del complejo funerario.

El marco interior de la puerta (Fig. 8) también estaba construido con un dintel que apoyaba sobre dos pilares, separados entre sí 1.53 metros, con bloques de piedra caliza, de los que actualmente sólo quedan restos de la parte inferior (2.08-2.01 metros de altura). El recercado de la puerta, de 0.49 metros de ancho, ahora es vertical, totalmente independiente del muro en el que está situado y está decorado con una columna vertical de inscripciones jeroglíficas (que se conserva incompleta).

Los paramentos laterales interiores, las jambas, también fueron decorados con la imagen del propietario del complejo funerario (Fig. 9), aunque actualmente sólo se conservan la parte inferior. La figura del propietario de 


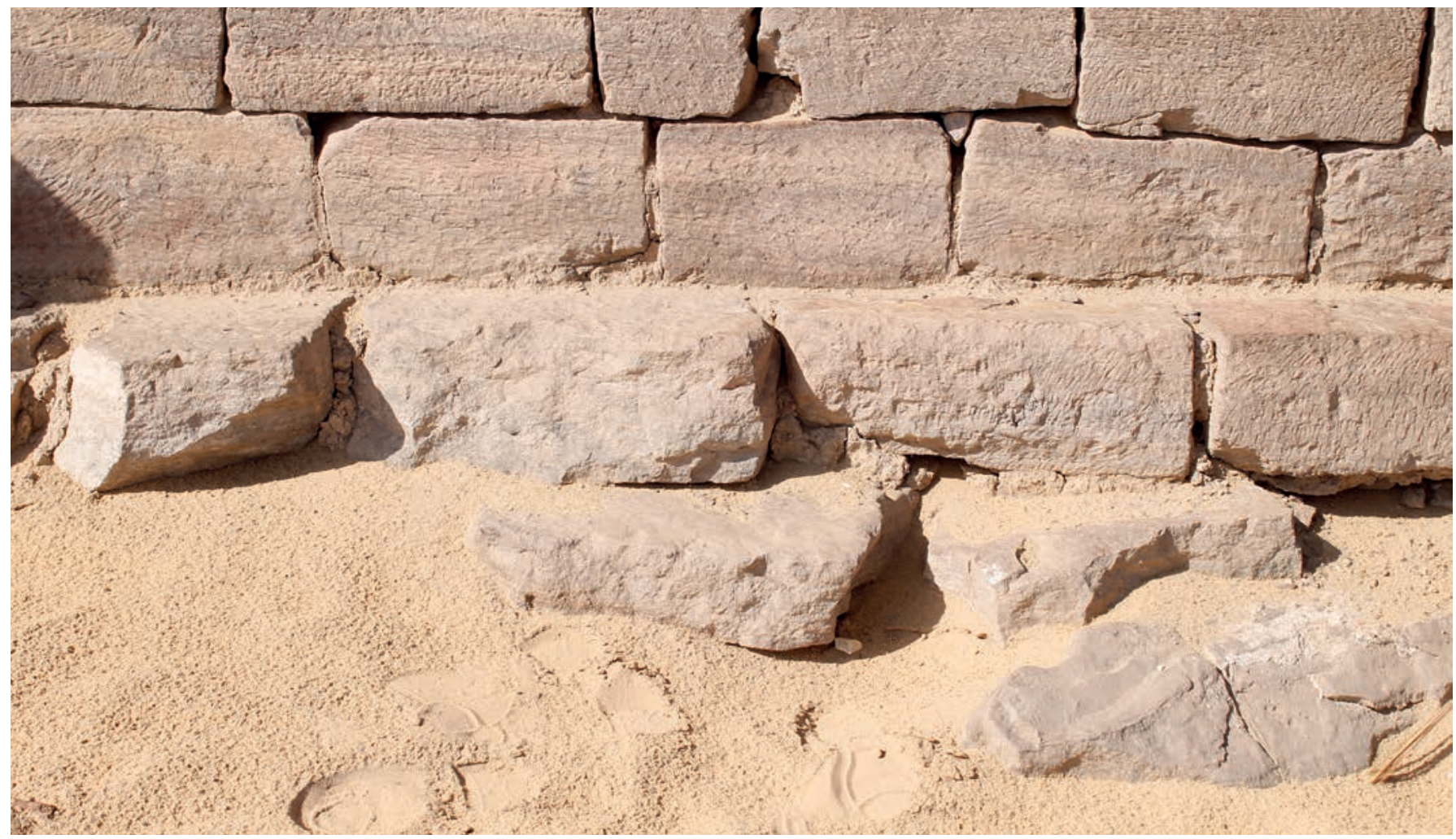

Figura 6. Cimientos en el extremo sur del muro delantero del patio de QH36.

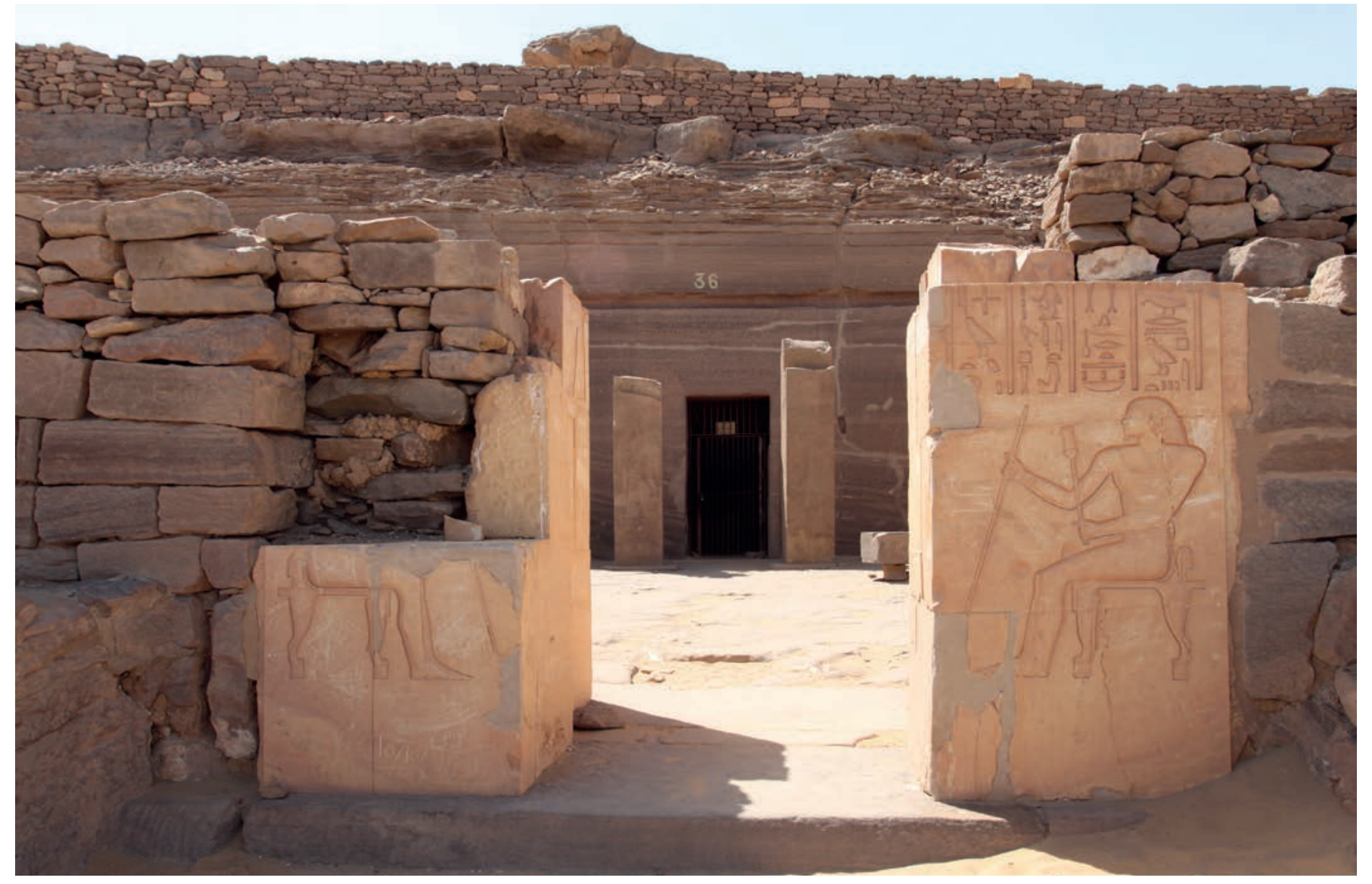

Figura 7. Fachada exterior de la puerta de acceso al patio exterior de QH36. 


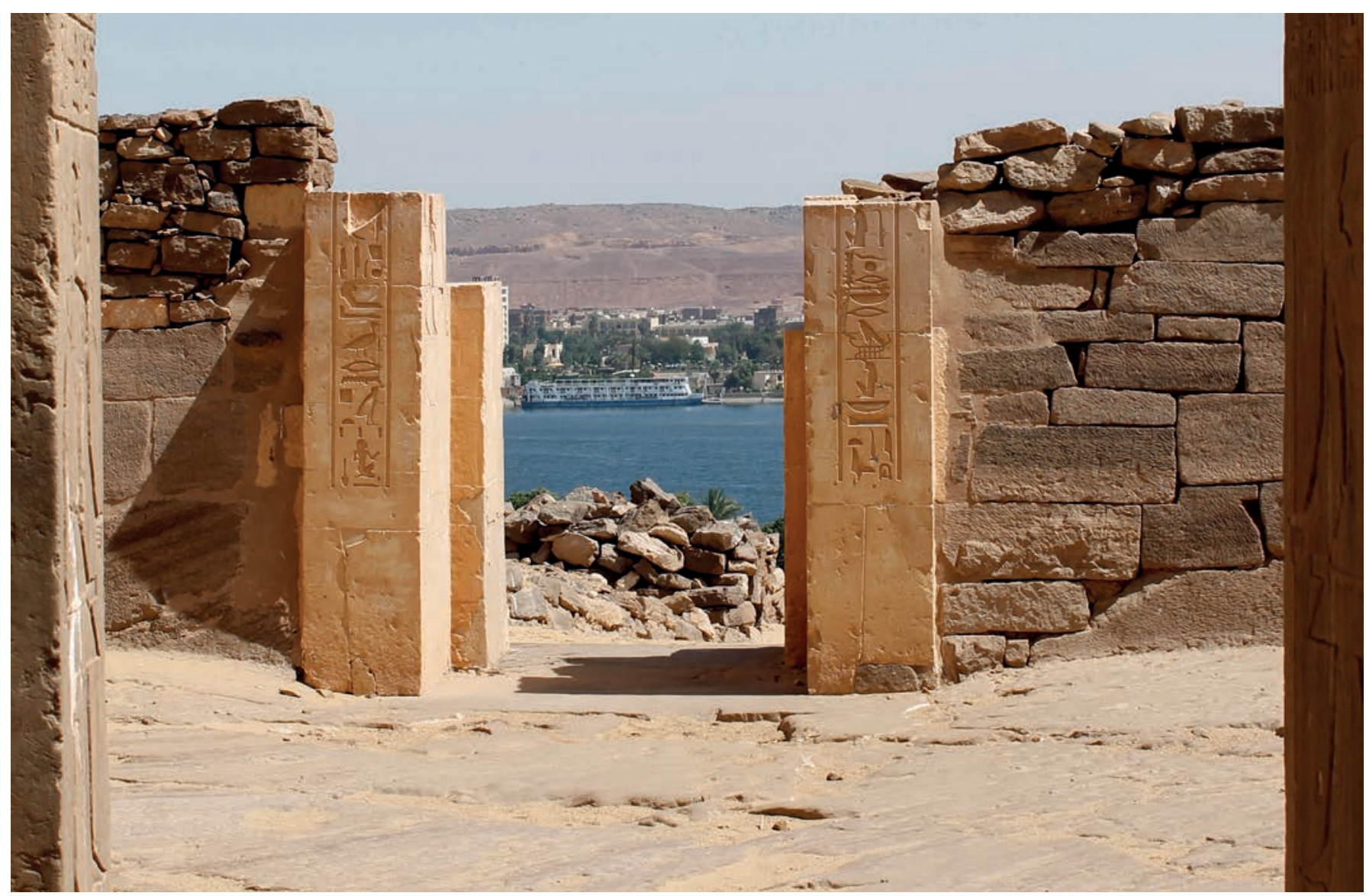

Figura 8. Fachada interior de la puerta de acceso al patio exterior de QH36.

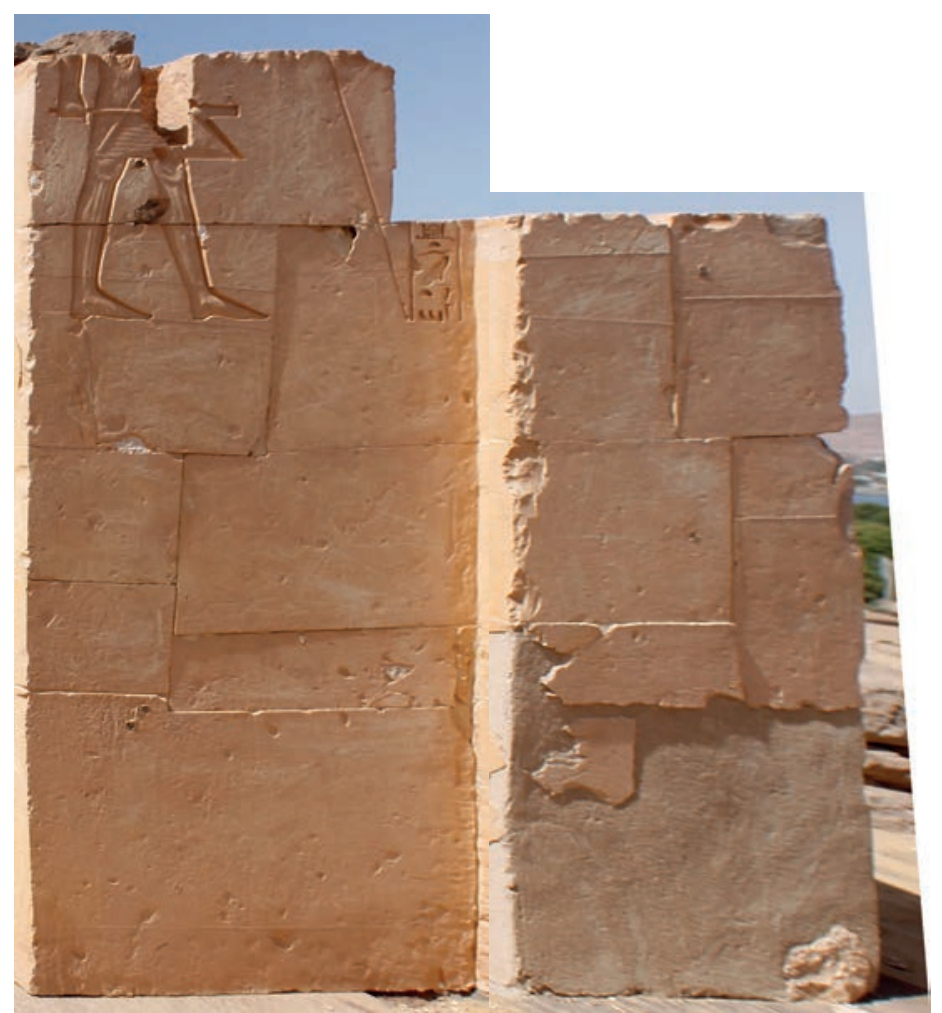

Figura 9. Jamba norte de la puerta de acceso al patio exterior de QH36. 
la tumba está representada de pie, mirando hacia las escaleras, vistiendo una falda corta plisada, y portando en una mano un largo bastón y en la otra el cetro sekhem. Además, hay una columna de inscripciones jeroglíficas situada justo delante de esta figura.

En los restos conservados de la puerta se observa cómo se realizaba la unión entre bloques, por su parte superior, mediante grapas de madera con forma de doble cola de milano. Su utilización era habitual en las construcciones durante este periodo. Por ejemplo, en Lisht se han encontrado gran cantidad de grapas de madera utilizadas en muros y cimentaciones del complejo funerario de Senwosret I (Arnold 1992: láms. 110-112). También existen ejemplos de cola de milano del Reino Nuevo, como en el complejo de Hatshepsut en Deir el-Bahari, o en el templo ptolemaico de Kom Ombo. En realidad, el sistema es tradicional y se usa desde el Reino Antiguo, por ejemplo, en el templo de la esfinge de Giza, de la Dinastía IV (Clarke y Engelbach 1990: 112-113, figs. 122-124, y 193, fig. 230).

En su momento contó con una puerta de madera, ahora desaparecida, colocada a haces de las jambas interiores del hueco, de una hoja abatible que abría hacia el interior del patio, con giro de izquierda a derecha, sobre un pivote encajado en varios orificios practicados en el suelo y probablemente, en las jambas y/o dintel del hueco de la puerta.

De las pocas puertas de madera existentes en la actualidad se puede mencionar la del Museo Metropolitano de Nueva York, procedente de la tumba MMA509 de Deir el-Bahari (pieza núm. MMA 23.3.174a) de principios de la Dinastía XII, el mismo periodo que la tumba. Otras puertas de madera, parecidas a la que debió estar colocada aquí, han sido publicadas por Clarke y Engelbach (1990: 163, fig. 185).

\section{Fachada porticada}

La fachada del hipogeo fue cortada directamente en la roca, ligeramente ataludada, y sus superficies fueron talladas y pulidas, presentando un acabado liso sobre el que destaca su decoración en altorrelieve que representa distintas escenas de la vida cotidiana de su propietario.

Estaba presidida por un pórtico (Fig. 10) compuesto por seis pilares monolíticos de piedra arenisca, que aún se conservan en parte, decorados en todas sus caras con relieves rehundidos representando al dueño de la tumba de pie, con el bastón y el cetro sekhem, mirando hacia el exterior del complejo, los dos centrales contienen pequeñas biografías del propietario en las caras que dan al eje del hipogeo, y otros dos pilares extremos inclinados con forma de pilastras embutidas en las paredes laterales del patio, a los que se adosan.

Los pilares están colocados sobre pequeños resaltes tallados en la roca, a modo de basas, orientados de manera que sus caras frontales y posteriores no muestran las vetas de los estratos del bloque de piedra que, por el contrario, se pueden observar en sus caras laterales (Fig. 11).

Sobre los pilares apoyaría un arquitrabe, compuesto por dinteles monolíticos de piedra, de longitud igual a la separación entre los ejes de los pilares de los que, en la actualidad, sólo se conservan dos de ellos (Fig. 12). Éstos, decorados con una línea de inscripciones en su cara vista, por sus dimensiones podrían ser los que estaban situados en la mitad norte del pórtico, entre el pilar del extremo y la pilastra, y entre dos pilares contiguos (Müller 1940: 18-19).

Además, el patio cuenta con dos pequeños naoi, tallados directamente en la roca, cada uno de ellos en un extremo de la nave interior del pórtico, que probablemente sirvieron para que la población realizara el culto funerario dentro del patio, sin tener que acceder al interior del hipogeo.

\section{OBJETIVOS}

El objetivo de este artículo es aportar la reconstrucción gráfica "ideal" de los espacios exteriores del complejo funerario QH36 (Sarenput I), uno de los pocos ejemplos conocidos de arquitectura funeraria privada del Reino Medio, junto a la tumba P.10.1, de Djefaihapi I, en Assiut, y las tumbas $n^{\circ} 7$, de Wakha I, $n^{\circ} 8$ de Ibu y n ${ }^{\circ} 18$, de Wakhka II, en Qaw el-Kebir, donde los complejos de los gobernadores son de gran escala y pueden asemejarse a las construcciones monumentales de los monarcas de estos momentos.

Para ello, previamente, se ha elaborado un completo levantamiento de planos de plantas, alzados y secciones del estado actual del complejo funerario, especialmente, de su recinto exterior.

\section{METODOLOGÍA}

El dibujo de arquitectura, caracterizado por la definición de las propiedades geométricas y constructivas a través de planos de planta, alzados y secciones, entendido en 


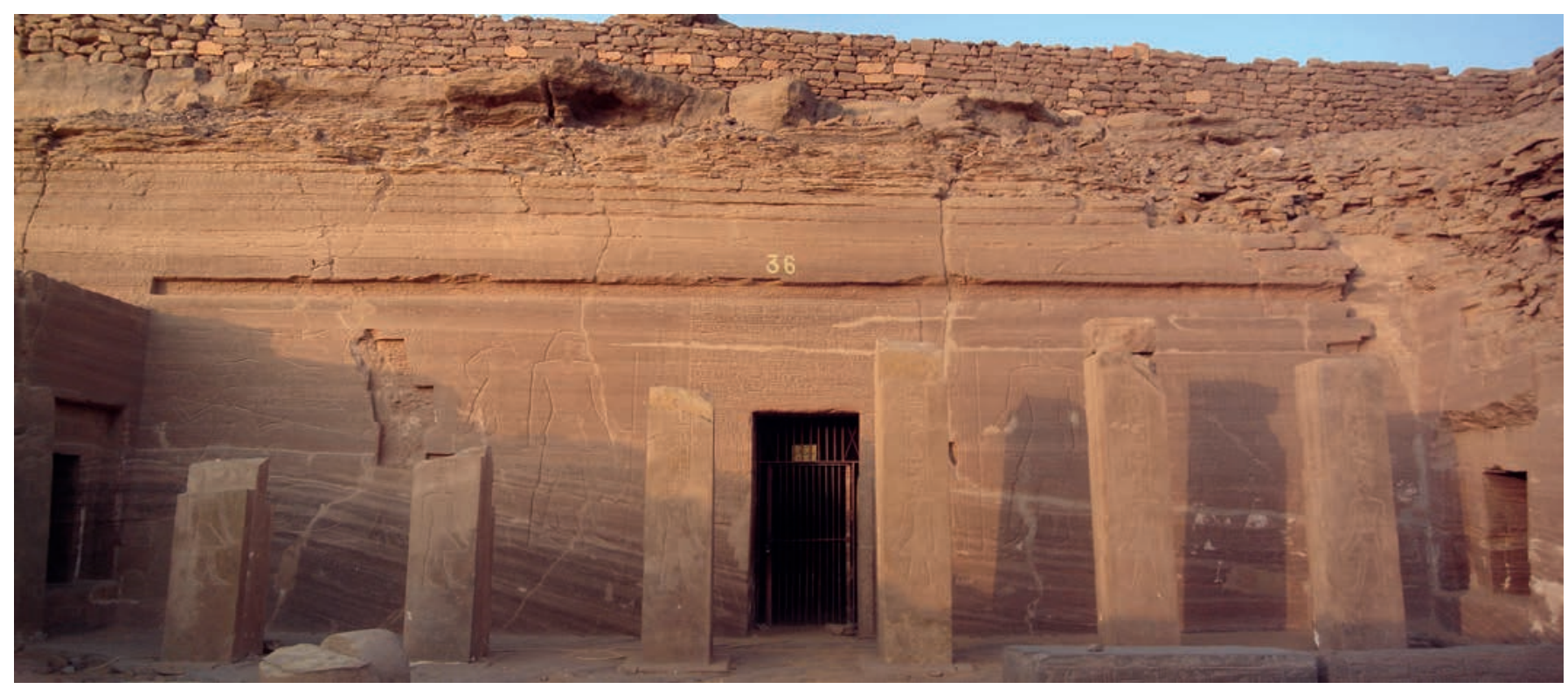

Figura 10. Fachada porticada del complejo funerario de Sarenput I (QH36).

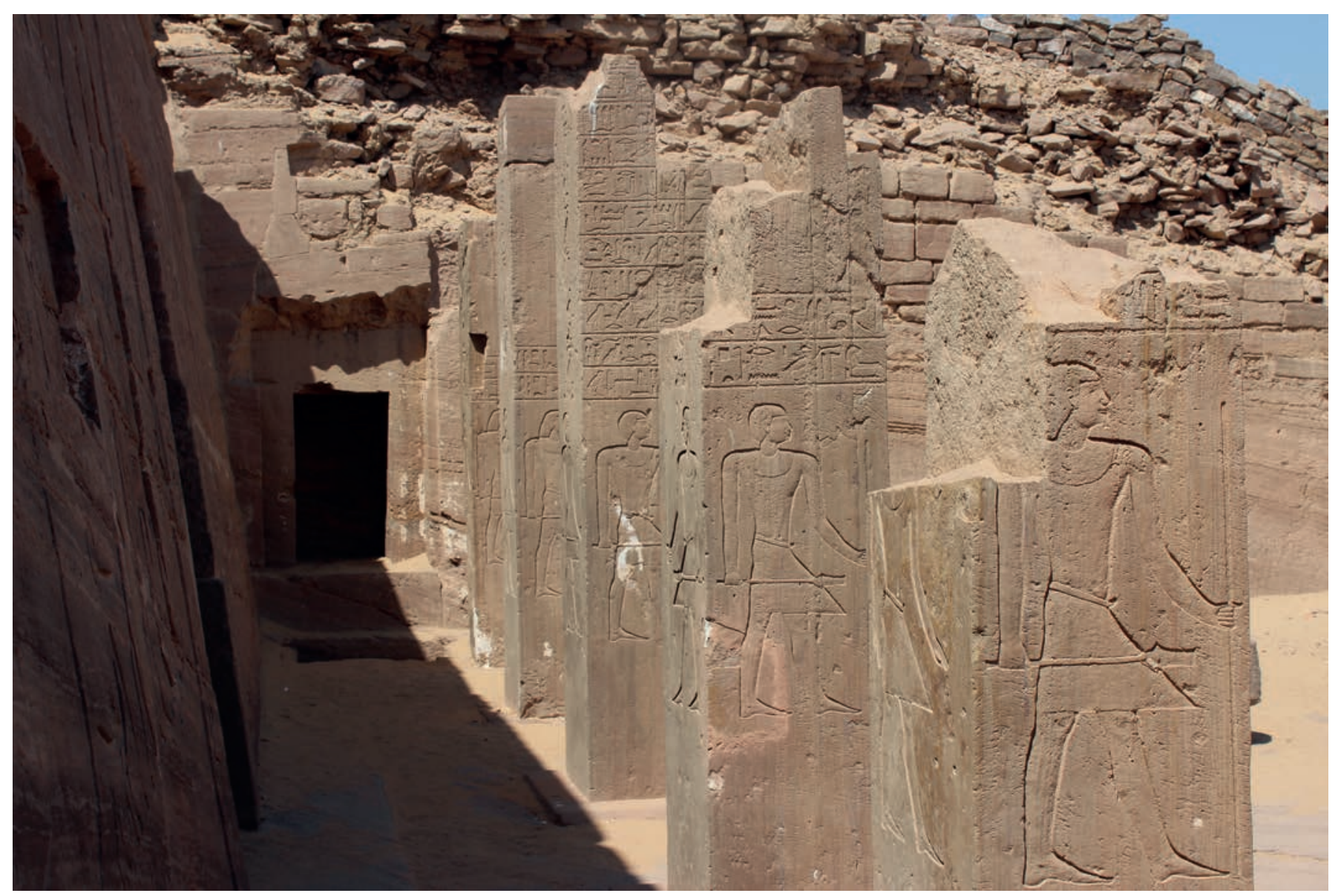

Figura 11. Nave interior del porche porticado del complejo funerario de QH36. 


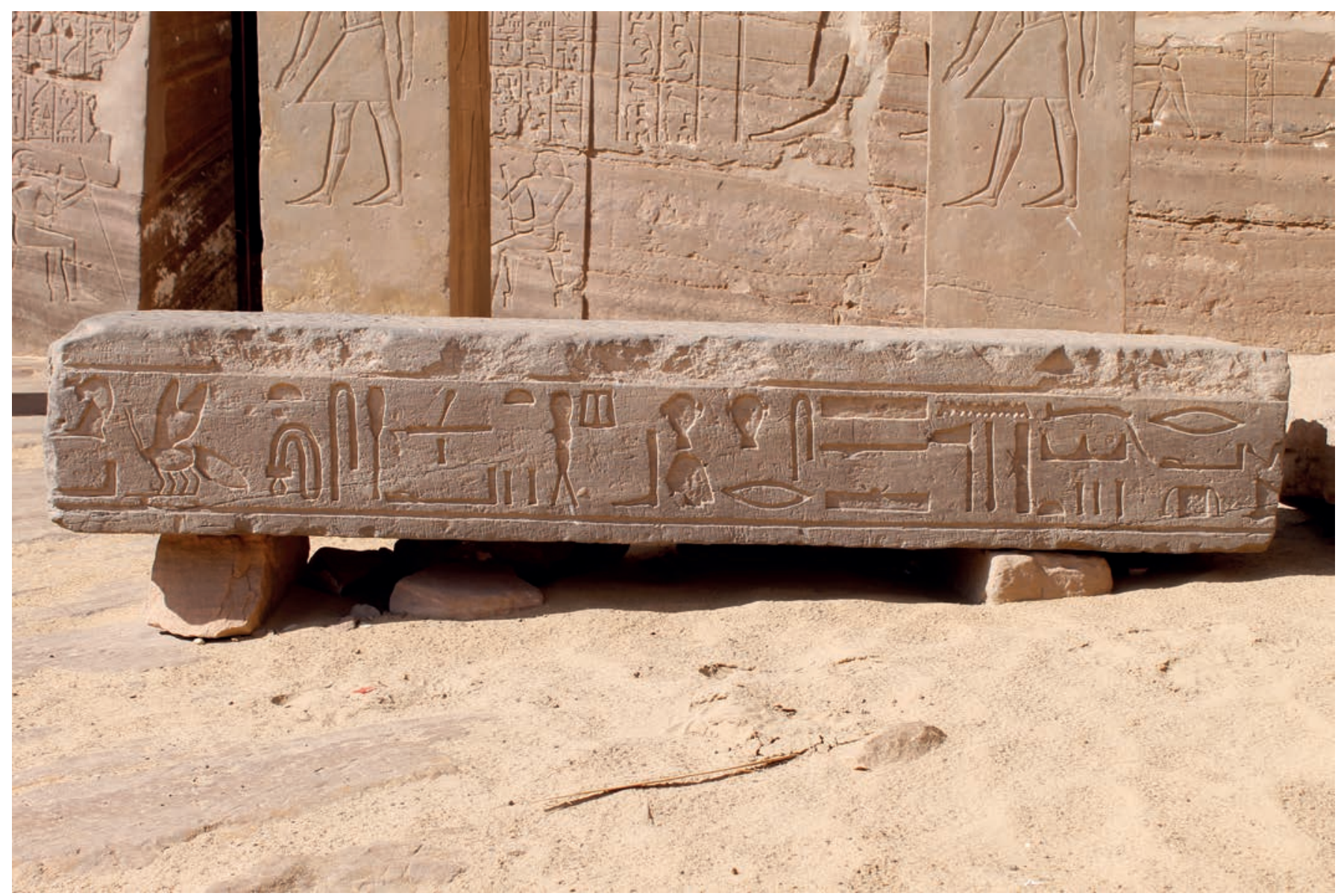

Figura 12. Restos del arquitrabe en el suelo del patio del complejo funerario de QH36.

su vertiente bidimensional, ha sido y sigue siendo hoy en día el método de representación gráfica por excelencia de los edificios históricos. La elaboración de esta planimetría supone un avance en el conocimiento y la difusión del monumento, al implicar un análisis geométrico y constructivo, convirtiéndose en un auténtico proceso de investigación, y la base para la realización del modelo tridimensional (Martín Talaverano 2014).

Los planos más completos y actualizados existentes hasta la fecha del complejo funerario QH36 fueron elaborados por F. Martínez Hermoso (2012), durante la campaña arqueológica 2012, tomando como base los datos obtenidos de primera mano, con la ayuda de un nivel láser, teodolito y mira, colocados en el eje central del hipogeo para obtener, principalmente, las inclinaciones de suelos y techos de los distintos espacios del interior del hipogeo.

A partir de esta planimetría, durante la campaña 2017, se decide actualizar, y en su caso corregir, la documentación gráfica del recinto exterior del complejo siendo suficiente para ello la medición desde una única estación total ubicada en el encuentro de dos ejes ortogonales entre sí y con los muros perimetrales del patio exterior, complementada con una completa serie de fotografías rectificadas (fotogrametría bidimensional), que ha permitido conocer con mayor exactitud, por ejemplo, la inclinación de los muros perimetrales y la posición de los elementos arquitectónicos existentes dentro del patio exterior del complejo.

Por otro lado, uno de los principios de la Carta de Londres para la aplicación de la visualización asistida por ordenador en el campo del Patrimonio Cultural (Denard 2009) y de la Carta de Sevilla (Carta de Sevilla 2012) basada en la anterior pero tomando en consideración el carácter específico de la Arqueología Virtual, es la de garantizar que el método utilizado en la reconstrucción hipotética de un edificio histórico se haya aplicado con rigor intelectual y técnico, debiendo éste dejar claro las diferencias entre evidencia e hipótesis, así como los distintos niveles de probabilidad.

De acuerdo con este principio, para la creación del modelo de reconstrucción del recinto exterior del 
complejo funerario QH36, se ha trabajado en dos niveles completamente distintos de conocimiento:

a) Evidencias:

Los elementos arquitectónicos conservados "in situ" (parcialmente) como la parte inferior de la puerta de acceso al patio, de los pilares del pórtico de fachada y otros elementos constructivos encontrados en el recinto exterior del complejo funerario que podrían volver a situarse en su posición originaria, así como una decena de bloques de coronación del muro del patio y un par de dinteles del pórtico de fachada, que permiten su reconstrucción garantizando su autenticidad, según las evidencias arqueológicas encontradas.

\section{b) Hipótesis:}

Los elementos arquitectónicos de los que no han quedado evidencias, como las losas del techo y la cornisa de remate del pórtico de fachada, o el dintel y la cornisa de remate de la puerta del patio, que no se pueden reconstruir a partir de otros ejemplos similares de la necrópolis ya que los complejos funerarios contemporáneos nunca se llegaron a terminar ya que, habitualmente, eran abandonados inconclusos, debido a la muerte de su propietario antes de finalizar las obras.

En este segundo caso, se han adoptado decisiones interpretativas, sustentadas en una sólida investigación y documentación histórica y arqueológica que garantizan un modelo con rigurosidad y veracidad histórica. Se ha propuesto reconstruir virtualmente estos elementos arquitectónicos, de la manera más aséptica posible, pero con un grado de certeza riguroso, basado en los pocos ejemplos conocidos de la arquitectura de prestigio contemporánea a la construcción del complejo funerario QH36.

Por ejemplo, el complejo funerario de Mentuhotep II, en Deir el-Bahari, del que apenas quedan algunos restos, estaba constituido por dos terrazas porticadas superpuestas. Detrás, al pie ya del acantilado y excavados en la roca, se encontraban un patio porticado, una sala hipóstila, la tumba del rey, la zona consagrada al culto real, y las tumbas y capillas de los miembros femeninos de la familia real (Naville 1910: pls. XXIII-XXIV; Winlock 1942; Arnold 1979).

Del complejo funerario de Senwosret I, en Lisht, se conoce su planta a partir de sus restos, los mejores preservados del Reino Medio. En torno a la pirámide del rey y del templo funerario fueron construidas la pirámide del $K a$, dedicada al culto, y otras nueve pirámides de las reinas, así como las mastabas de sus cortesanos más importantes (Arnold 1992).

Las tumbas privadas $\mathrm{n}^{\circ} 7$, de Wakha I (Senwosret II), y n ${ }^{\circ} 18$, de Wakha II (Senwosret III), en Qaw elKebir, unas de las más monumentales de este período, contaban con una zona exterior donde se sucedían varias terrazas porticadas que se iban adaptando al terreno, de las que no queda nada, y otra zona excavada en la roca (casi en ruinas), pudiéndonos hacer una idea de su arquitectura sólo a partir de las reconstrucciones realizadas por Hans Steckeweh (1936: pls I-II,V-VI).

El Templo de Montu, construido por Senwosret I, en Tod, representa uno de los ejemplos más claros de templo evolucionado del Reino Medio, con su diseño simétrico de gran precisión y la incorporación de varias cámaras de culto adyacentes al santuario principal. Se conoce a través de los restos conservados de la planta (Bisson de la Roque 1937: 6-13, pl. II; Winlock 1943: 270).

Y por último, la "Capilla Blanca", que debe su nombre a la piedra caliza blanca con la que se construyó, edificada para la fiesta de renovación del poder real de Senwosret I. Es el único monumento reconstruido materialmente, a partir de sus bloques originales que habían sido reutilizados como cimientos en el templo de Karnak (Chevrier 1938: 8-9; Borchardt 1938: 56-57, fig. 19; Lacau et Chevrier 1956).

\section{ESTADO DEL ARTE}

El complejo funerario QH36 fue descubierto, excavado parcialmente y documentado (de forma deficiente) por Grenfell a finales del siglo XIX, y publicado por Wallis Budge en Excavations made at Aswan by Major-General Sir F. Grenfell during the years 1885 and 1886 (1887) junto a otros tres importantes complejos funerarios de la necrópolis QH31, QH25 y QH26, estos dos últimos del Reino Antiguo. Sin embargo, Budge sólo hace una breve descripción de los elementos arquitectónicos del patio exterior de QH36 que se sobresalían tímidamente por encima de la arena: la puerta del patio exterior y los pilares del pórtico de fachada del complejo funerario (1887: 34).

En 1894, Jacques de Morgan publica el primer trabajo global sobre Qubbet el-Hawa, Catalogue des monuments et inscriptions de l'Égypte Antique. Haute 
Égypte. Tome Premier: de la frontière de Nubie â Kom Ombos (1894). Sobre el complejo funerario QH36, hace una breve descripción del mismo, centrándose principalmente en las escenas que decoran la puerta de entrada al patio, los pilares del pórtico y el muro de la fachada (1894: 179-188). De Morgan presenta un plano esquemático del complejo funerario que incluye el patio exterior del complejo y el pórtico de fachada, proponiendo tímidamente una reconstrucción de éste último (1894: 179).

En 1936, Hans Wolfgang Müller publicó Die Felsengräber der Fürsten von Elephantine aus der Zeit des Mittleren Reiches (1940), un estudio monográfico acerca de los complejos funerarios del Reino Medio (QH36, QH31, QH32 y QH30, ordenados cronológicamente). En el caso del complejo funerario QH36, hace una descripción detallada del patio exterior y la puerta de acceso al mismo, así como del pórtico de fachada y de los nichos situados en los dos extremos de la galería porticada (1940: 16-20), y propone la reconstrucción del muro y la puerta de entrada del patio exterior (1940: fig. 3) con un diseño basado en ejemplos del Reino Antiguo como el complejo piramidal de Kefrén, en Guiza (Dinastía IV).

Por último, en el marco de los trabajos de investigación que está llevando a cabo el equipo del proyecto Qubbet el-Hawa, de la Universidad de Jaén, destacan dos trabajos sobre el complejo funerario QH36: el primero, La tumba de Sarenput I. Arquitectura y Representación Gráfica (Martínez Hermoso 2012), un estudio arquitectónico preliminar del complejo funerario y, el segundo, Sarenput I: Estudio Histórico de un Nomarca de Ta-Seti a Principios de la Dinastía XII (García González 2011), donde se hace un interesante análisis iconográfico del mismo.

\section{RESULTADOS Y DISCUSION}

Funcionalmente, el complejo funerario de Sarenput I se puede dividir en dos partes fundamentales: por un lado, la parte pública del monumento, que incluye el muro exterior del complejo y su puerta monumental, el patio, la fachada porticada, y la capilla funeraria compuesta por una sala de pilares y una cámara de culto al gobernador conectadas por un largo y estrecho corredor abovedado. Por otro lado, existen una serie de pozos y cámaras subterráneas que componían la parte íntima, secreta e inaccesible de la tumba, donde quedaban enterrados el gobernador y otros difuntos dependientes, así como sus ajuares. Por lo tanto, el análisis y reconstrucción aquí presentes corresponde al 50 por ciento de la parte pública, quedando relegado el resto del complejo a otros estudios posteriores o distintos.

Ahora bien, si para la descripción de los elementos arquitectónicos del recinto exterior, en su estado actual, se ha seguido el sentido de avance del visitante, desde el exterior del complejo funerario hacia el interior del hipogeo, ahora, para el análisis de cada elemento arquitectónico retrocedemos en sentido contrario, comenzando por el elemento arquitectónico mejor conservado, la fachada porticada (Fig. 13) hacia el exterior del complejo funerario donde existen menos restos arquitectónicos y evidencias arqueológicas.

\section{Reconstrucción del pórtico de pilares}

Los pilares del pórtico de fachada son de sección recta, con unas dimensiones medias de ancho de sus caras frontal y posterior de 0.60 metros y de sus caras laterales de 0.56 metros, encontrándose situados unos de otros a una distancia de unos 1.50 metros, salvo en el caso de los dos pilares centrales donde su separación es algo mayor (1.59 metros).

La altura libre interior de la nave del pórtico, medida desde el suelo del patio hasta la cara inferior del techo fue de 3.90 metros, dimensión que es conocida gracias al rebaje existente en el plano de la fachada tallado directamente en la roca, de 23 centímetros de altura, que probablemente sirvió para apoyar losas de piedra, de unos 2.20 metros de longitud y 20 centímetros de espesor, aunque en la actualidad no se conserva ningún resto de este techo.

Los dinteles que conectaban los pilares, debían tener una longitud media de 2.10 metros (2.40 metros en los vanos extremos), y un canto de 0.35 metros, e iban a estar unidos, en su parte superior, mediante grapas de unión de madera con forma de doble cola de milano, como puede observarse en uno de los que se conservan en el patio.

Además, la parte frontal del pórtico, continuación de las losas del techo, probablemente, habría sido acabada mediante bloques de piedra, decorados con una moldura toro y una cornisa caveto o nácela (de cuarto de círculo cóncavo), de igual altura que la altura de los arquitrabes (0.35 metros).

De esta manera, la altura total del pórtico de pilares, desde el nivel del pavimento del patio hasta la parte 
alta de la cornisa caveto, sería de unos 4.25 metros, aproximadamente.

Por ejemplo, Dieter Arnold propone justo esta misma solución para la reconstrucción de los pórticos de fachada del templo de Mentuhotep II. Las losas del techo apoyan en un rebaje tallado en el muro de fachada y en dos filas de dinteles paralelos a la fachada, rematando ésta con una cornisa caveto situada al mismo nivel que las losas, y de la misma altura que el arquitrabe (37.50 centímetros) (1979: 13-16, fig. 5c, lám. 28). En este mismo monumento, las losas del techo de la sala hipóstila eran de 22.50 centímetros de espesor (similares a la propuesta para el techo de la nave del pórtico de QH36), y apoyaban sobre arquitrabes de 37.50 centímetros de altura, siendo la cornisa también de igual espesor (1979: 36-37).

Además, sobre el tallado en la roca de una hendidura horizontal para el apoyo de las losas del techo, encontramos ejemplos similares en Qaw el-Kebir, en las tumbas $\mathrm{n}^{\circ} 7$, de Wakha I (Senwosret II) y $\mathrm{n}^{\circ} 18$, de Wakha II (Senwosret III). En la pared oeste de sus salas hipóstilas (donde comienza el hipogeo) fueron talladas hendiduras similares a la de QH36, a una la altura de 2.95 metros (Petrie 1930: 2, pl. II.5) y 3.56 metros (ibidem: 4, pl.V.3), respectivamente, desde el suelo hasta la cara inferior del techo (altura de pilar más arquitrabe).

Y sobre la utilización de la cornisa caveto, también las encontramos en los patios de las tumbas de Qaw elKebir (Senwosret II-III) (Petrie 1930: 4), o en Karnak, en la "Capilla Blanca" de Senwosret I, donde las losas del techo apoyan sobre arquitrabes (de 2.20 y 1.75 metros de longitud y 0.54 metros de canto) que trasmiten las cargas sobre dieciséis pilares monolíticos, de sección cuadrada $(0.63 \times 0.63$ metros $)$ y rectangular $(0.63 \times 0.95$ metros) de dimensiones muy similares a los de QH36 (Lacau y Chevrier 1956: pls. 4-7).

Sin embargo, no existe la certeza de que el pórtico fuese terminado completamente. Por un lado, el hecho de que sólo se conserven dos de los siete dinteles, podría indicar que no se recibieron en obra todos estos elementos constructivos. Además, los dinteles conservados se encuentran calzados en el suelo del patio, probablemente, durante la recepción en obra para facilitar los trabajos de su decoración. Asimismo, el dintel extremo tiene aspecto de inacabado ya que, en su cara superior, carece del tallado en forma de cola de milano que servía para introducir la llave de unión entre bloques. Y a todo esto hay que sumar el hecho de que no se ha conservado ningún resto ni de las losas del techo ni de las cornisas de remate del pórtico, probablemente, también sin recibir en obra.

Pero por otro lado, es bien conocido que a pesar de que numerosos complejos funerarios se quedaban sin terminar debido a, entre otras cosas, la muerte del dueño de la tumba, era muy normal extraer bloques para reutilizarlos en otros edificios. El hecho de que solamente haya dos bloques en el complejo no es señal de que no hubieran llegado más, al igual que no tenemos el entramado en piedra del techo de este pórtico. Además, la decoración del muro de fachada, donde hay escenas y textos, así como alrededor de la puerta de acceso al interior del hipogeo, muestra un avanzado estado de trabajo ya que lo normal sería terminar las inscripciones y decoración cuando estuviese terminado el pórtico.

En realidad, los monumentos egipcios eran constantemente saqueados y mucho material ha desaparecido de numerosas tumbas en este yacimiento y en otros del mismo período. Por ejemplo, en las tumbas del Reino Medio de Deir el-Bahari quedan solamente los hipogeos pero no los bloques, estelas y estructuras de adobe que sabemos que decoraban las tumbas.

Sea como fuere, lo que está claro es que la planificación del complejo funerario incluía la construcción de un pórtico de pilares, de la manera que se ha descrito en este apartado.

Queda en el aire una pregunta interesante ¿se puede considerar la reconstrucción de la fachada porticada de QH36 como el diseño arquitectónico con el que habitualmente se planificaron los exteriores de los complejos funerarios de la necrópolis durante este período? Y, en ese caso, ¿se podría trasladar esta solución arquitectónica al resto de los grandes complejos funerarios de la Dinastía XII (en sus correspondientes reconstrucciones virtuales ideales) aunque, finalmente, no se construyeran al quedar las obras inconclusas, con distintos grados de terminación según los casos?

\section{Reconstrucción del patio exterior}

El vaciado del patio exterior se realizó, siguiendo el método habitual utilizado en la necrópolis, eliminando la roca de arriba hacia abajo y del centro hacia los lados, cortando el plano de la fachada y de los muros laterales, ligeramente ataludados y, en último lugar, construyendo el muro delantero (Fig. 14).

De hecho, este último muro no tiene trabazón con los muros laterales, construidos primero, que se prolongan hacia el exterior entorno a un metro observándose, 


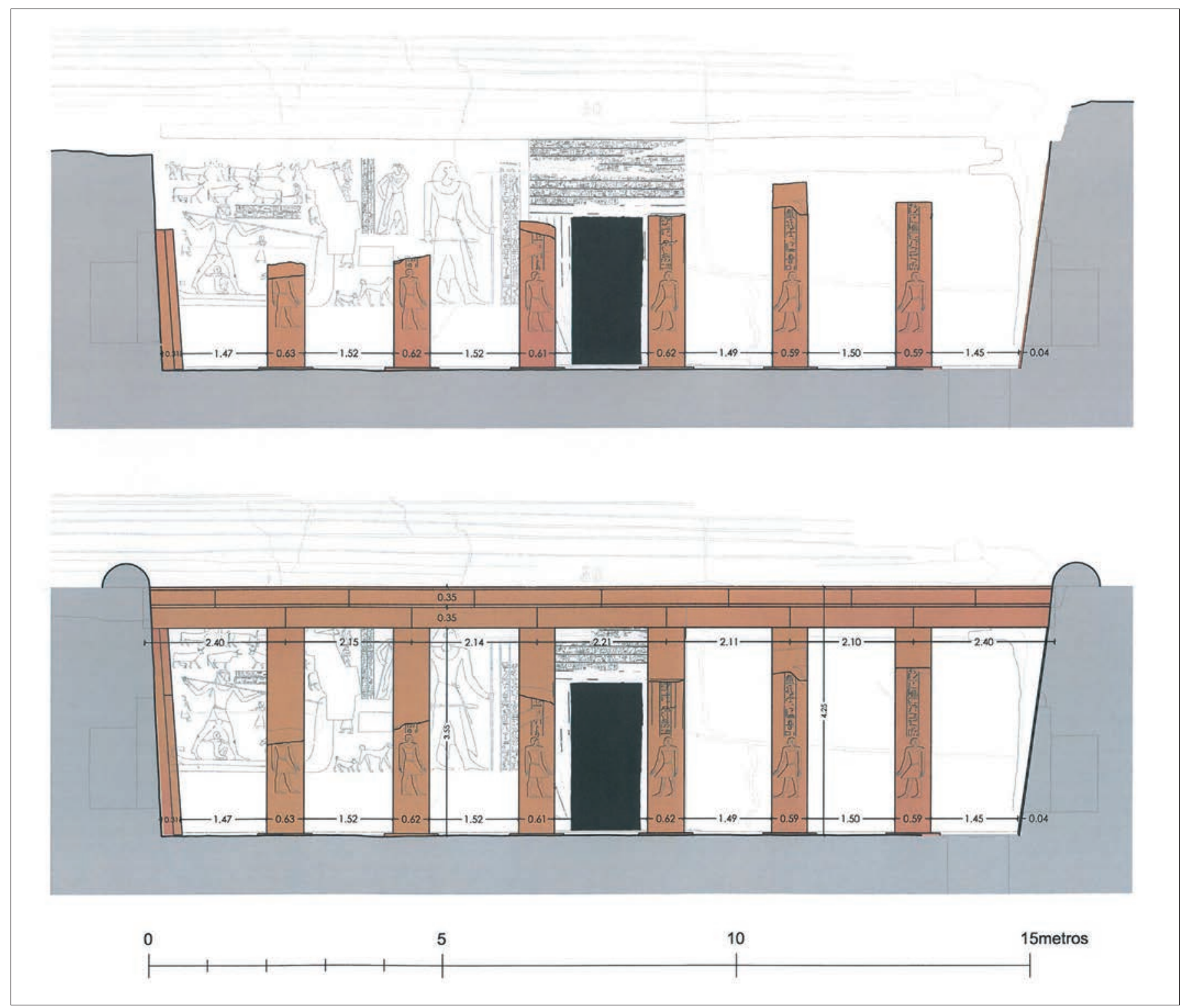

Figura 13. Pórtico de pilares que preside la fachada del patio del complejo funerario de Sarenput I (QH36). En la parte superior, estado actual; y en la inferior, reconstrucción.

además, en éstos últimos la línea de replanteo marcada para la pendiente de la cara exterior del muro delantero (Fig. 15).

Aunque no se conoce la altura del muro delantero, al conservarse sólo su parte inferior, ésta se puede calcular geométricamente a partir de las dimensiones conocidas de su base, de la inclinación de sus dos caras ataludadas y de los bloques de coronación del mismo.

La sección de los bloques de remate tiene forma de segmento circular, o segmento de un círculo limitado por una cuerda y el arco correspondiente. Tomando como base las dimensiones de los bloques, publicada por Müller (1940: 16-17), para el cálculo utilizamos la media de las dimensiones $(0.80$ metros de cuerda y 0.30 metros de altura). El ancho del muro en la base es de 1.70 metros y la inclinación de sus caras respecto al nivel horizontal del suelo es de $85.5^{\circ}$ por el exterior del patio, y de $82^{\circ}$ por el interior, la misma inclinación que la fachada del hipogeo.

A partir de estos datos podemos calcular geométricamente la altura del muro delantero del patio exterior, que alcanzaría unos 4.15 metros más el bloque de coronación lo hace un total de 4.45 metros, dimensión que iría aumentando ligeramente en los muros laterales a medida que se acercan a la fachada porticada, debido a la suave pendiente con que cuenta el suelo del patio. 


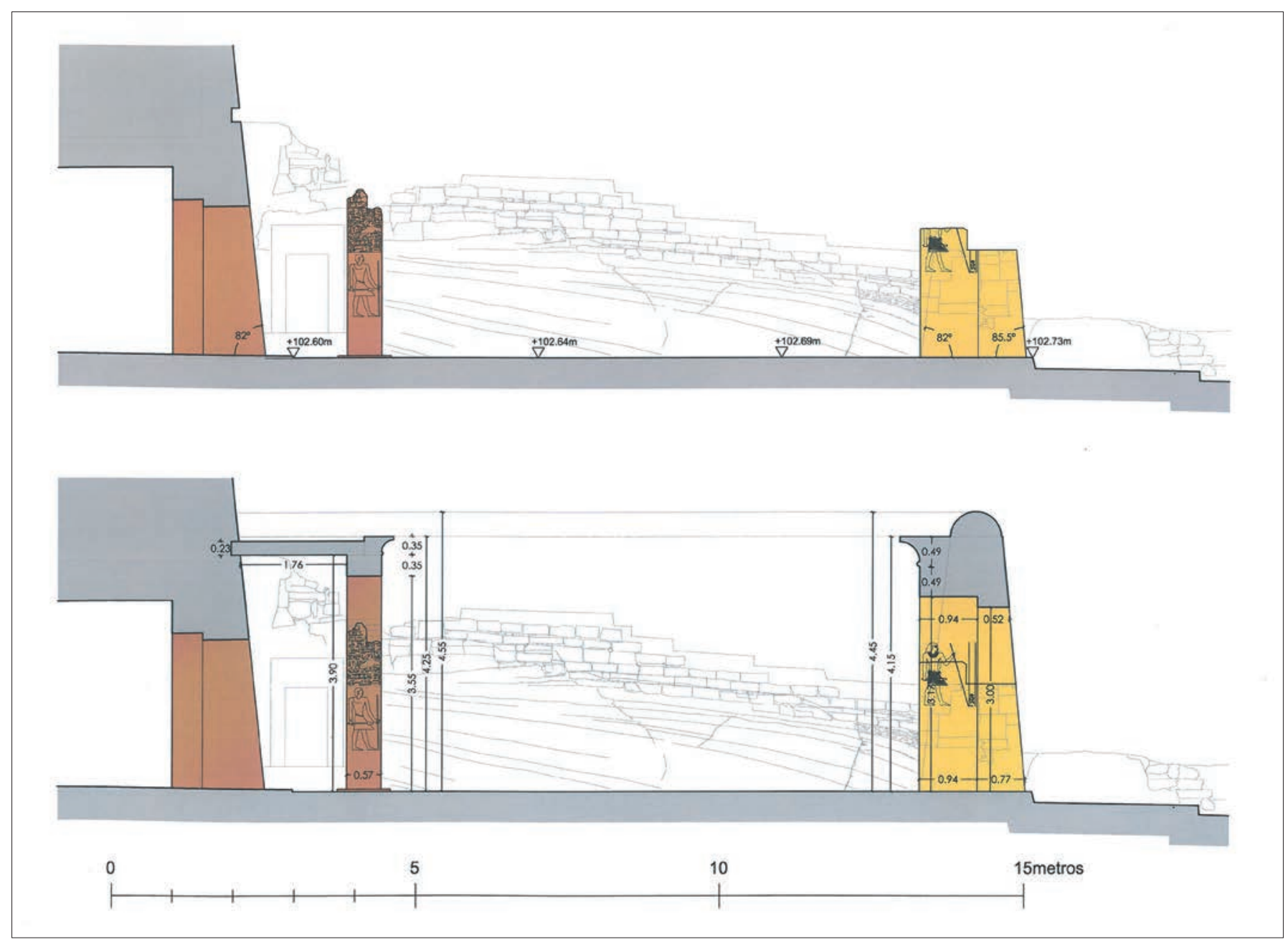

Figura 14. Sección del patio exterior del complejo funerario de Sarenput I (QH36). En la parte superior, estado actual; y en la inferior, reconstrucción.

Es importante señalar que la línea de la base de los bloques de coronación del muro coincide, sensiblemente, con la horizontal que pasa por la cara superior de la cornisa caveto que remata el pórtico de pilares por lo que, con toda probabilidad, en la planificación inicial del exterior del complejo funerario, se ajustaron todas estas alturas para hacerlas coincidir.

Este mismo sistema de cálculo fue utilizado, en 1981, por el Museo Metropolitano para reconstruir el muro de piedra que rodeaba el recinto de la pirámide de Senwosret I, en Lisht, a partir de su anchura en la base (2.625 metros), del ángulo que formaban sus paredes respecto a la horizontal del suelo $\left(82^{\circ}\right)$, y de los numerosos bloques de coronación, también de sección semicircular, encontrados en el recinto, obteniendo una altura total del muro de 5.49 metros (Arnold 1988: 59, fig. 19).

Hay que señalar, sobre la inclinación de las caras de los muros, que un ángulo de $82^{\circ}$ es una buena aproximación a un seked de 1/7 (81 $\left.52^{\circ}\right)$, relación egipcia entre el desplazamiento horizontal (en palmos) de la pared inclinada respecto a la vertical para una altura de un codo (7 palmos) (Arnold 1991: 10-16).

\section{Reconstrucción de la puerta de acceso al patio}

Aunque el complejo funerario QH36 fue el único de Qubbet el-Hawa que, en principio, fue completamente acabado su parte exterior (véase el apartado "Reconstrucción del pórtico de pilares"), no se conoce la altura de la puerta de acceso al patio delantero debido a que sólo se ha conservado la parte inferior de la misma. Hay que tener en cuenta que en la necrópolis no existen otros paralelos, ya que los trabajos en el exterior de los complejos funerarios nunca se llegaban a terminar porque se posponían hasta la fase final de construcción 


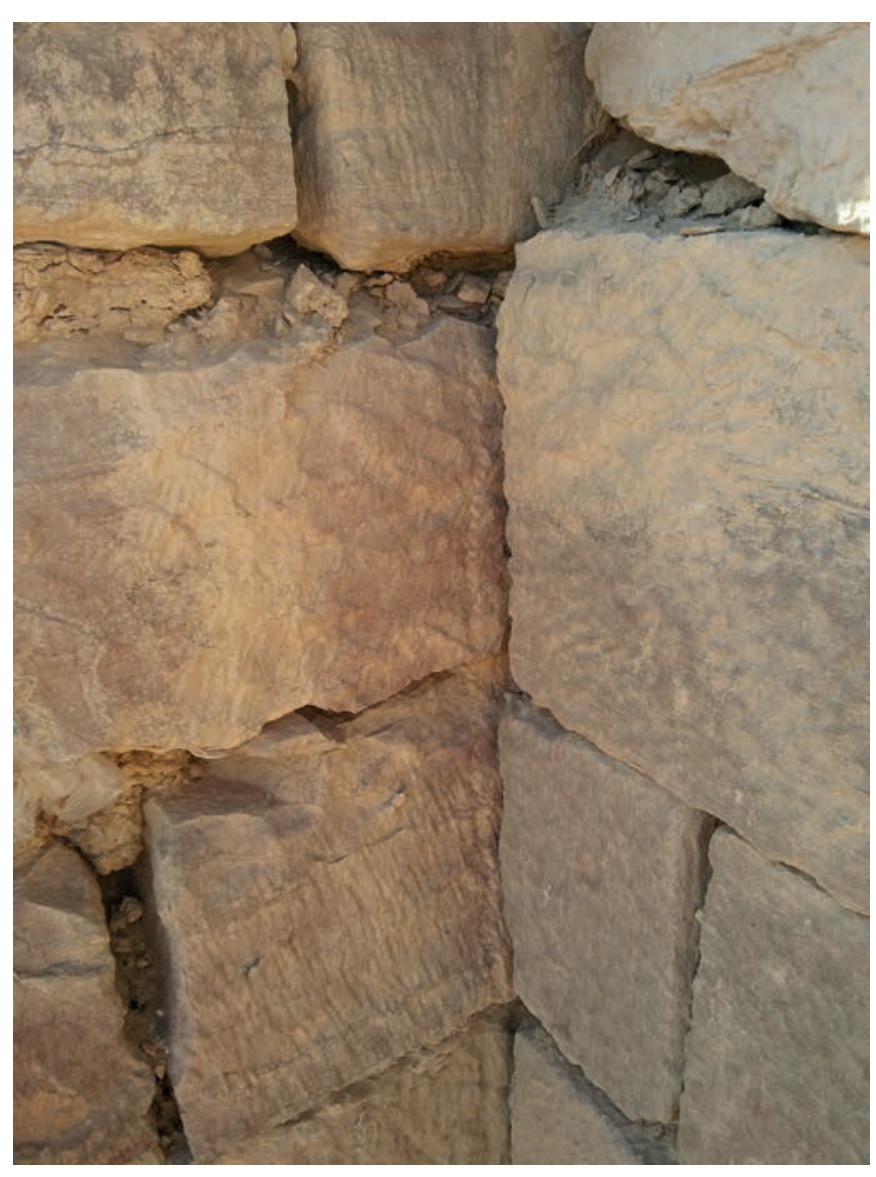

Figura 15. Encuentro entre el muro lateral sur y el muro exterior del patio de QH36.

y, habitualmente, éstos eran abandonados inconclusos debido a la muerte de su propietario antes de finalizar las obras.

No obstante, lo que sí se puede afirmar es que la altura y la esbeltez de las puertas de los complejos funerarios iba disminuyendo, de fuera hacia adentro, a medida que se avanza hacia el interior. Por ejemplo, en el monumental complejo funerario de Sarenput II (QH31) (Senwosret II-III) la puerta de acceso al interior del hipogeo, inacabada, mide 4.20 metros de alto por 1.05 metros de ancho (Martínez Hermoso et al. 2015; Martínez Hermoso 2017: 191-192); la puerta que separa la zona de recepción de la zona de culto 3.00 metros por 1.45 metros (Martínez Hermoso et al. 2015; Martínez Hermoso 2017: 263-266), y la puerta del santuario situado al final de la capilla 1.57 metros de alto por 1.05 metros de ancho (Martínez Hermoso et al. 2015; Martínez Hermoso 2017: 280-285).

De hecho, en Qubbet el-Hawa, las capillas de los complejos funerarios de los gobernadores del Reino Medio fueron planificadas como un templo (Martínez Hermoso 2017: 207). La disposición de sus espacios, desde la entrada del complejo funerario, y en dirección al santuario, la altura del techo disminuye progresivamente en cada dependencia, diseño que está estrechamente relacionado con el distinto tratamiento de la luz: el patio exterior está bañado de sol, en la sala hipóstila reina la penumbra puesto que la luz penetra en el interior a través de la apertura de la puerta del hipogeo situada frente a la nave central y, por último, en la cámara de culto con el santuario donde se alojaba la estatua del propietario de la tumba reina la oscuridad.

\section{Marco exterior}

El esquema de las puertas de muchas tumbas privadas del Reino Medio consta de un marco exterior, que sobresale ligeramente del plano de fachada decorado con inscripciones biográficas realizadas en relieve, con varias líneas horizontales sobre el dintel y columnas a cada lado de la puerta que finalizan con sendas figuras sedentes del propietario de la tumba.

En Qubbet el-Hawa sólo encontramos dos casos en el Reino Medio de puertas completamente terminadas: la puerta de entrada al pequeño hipogeo QH28 y la puerta de entrada a la parte excavada del complejo funerario QH36 (Martínez Hermoso 2017: 187-190).

En el complejo funerario QH36 se construyeron dos puertas, la de entrada al interior del hipogeo, que mide 2.50 metros de alto por 1.25 metros de ancho (idem), y la del santuario situado al final de la capilla, que mide 1.30 metros de alto por 0.70 metros de ancho (ibidem: 249-250).

Siguiendo esta norma, aunque el ancho de la puerta del patio exterior ( 1.27 metros) mide casi lo mismo que la de entrada al interior del hipogeo (1.25 metros), podemos afirmar que su altura debió de ser mayor.

De hecho, Müller propone en su reconstrucción del marco exterior de la puerta un valor de unos 2.80 metros de altura libre, basándose en la comparación entre las dimensiones conocidas de la puerta del patio con las de la puerta de la entrada al interior del hipogeo (Fig. 16), que es la única de este tipo que fue completamente acabada en la necrópolis (1940: 17-18).

Sin embargo, probablemente la altura libre de la puerta sería incluso aún mayor, ya que, aunque la relación entre la anchura y la altura de las puertas de los edificios egipcios no es constante, depende del sistema general de proporciones, en cada caso, con proporciones de huecos de puerta que variaban entre 1:2 a 1:3 (Arnold 2008: 74-75). 
Por ejemplo, en Lisht, la expedición del Museo Metropolitano reconstruyó una puerta de piedra caliza, situada junto a la entrada al recinto exterior del complejo funerario de Senwosret I, al sur de la calzada de acceso al templo funerario, a partir del ancho de 1.05 metros de la jamba. Cuando se descubrió la puerta se encontraba muy bien conservada, estimando que ésta debió alcanzar una altura entre 2.10-2.625 metros, dimensiones que, en realidad, responden simplemente a la proporción de una altura 2-2.50 veces el ancho de la puerta (Arnold 1992: 16-17, pl. 76).

Basándonos en estas últimas proporciones, y en el ancho de las columnas de los textos existentes en la base del pilar del lado norte del hueco de la puerta, nuestra puerta tendría unas dimensiones mayores, podría alcanzar casi 3.20 metros de altura libre máxima.

Al ajustar la altura de la puerta y dintel con la altura del muro delantero, obtendremos una altura libre de unos 3.00 metros y un dintel de unos 1.15 metros (con un margen de error de $+5 \mathrm{~cm}$.). Las proporciones de la puerta
(Fig. 17) son más parecidas a las dimensiones de la puerta de entrada al templo de Montu, construido por Senwosret I en Tod, reconstruida a partir de la parte inferior de las jambas y de varios fragmentos del dintel. A partir de un ancho de vano de 1.35 metros y un anchura total, incluyendo el recercado perimetral para los textos, de 3.00 metros (ancho del recercado, 0.83 metros) tendría una altura libre de puerta de 3.00 metros (igual que el ancho total de la puerta) y una altura total, incluyendo el dintel superior, de 4.27 metros (altura del dintel, 1.27 metros) (Bisson de la Roque 1937: 6-16; Badawy 1966: 83, fig. 34).

\section{Marco interior}

La altura libre del marco de la puerta que da al patio probablemente fuera de 3.17 metros, aproximadamente, resultado de sumar a la altura del marco exterior $(3.00$ m.) los 17 centímetros que reduce el vano del marco exterior a cada lado de la puerta, al ser dimensiones que están directamente relacionadas entre sí.

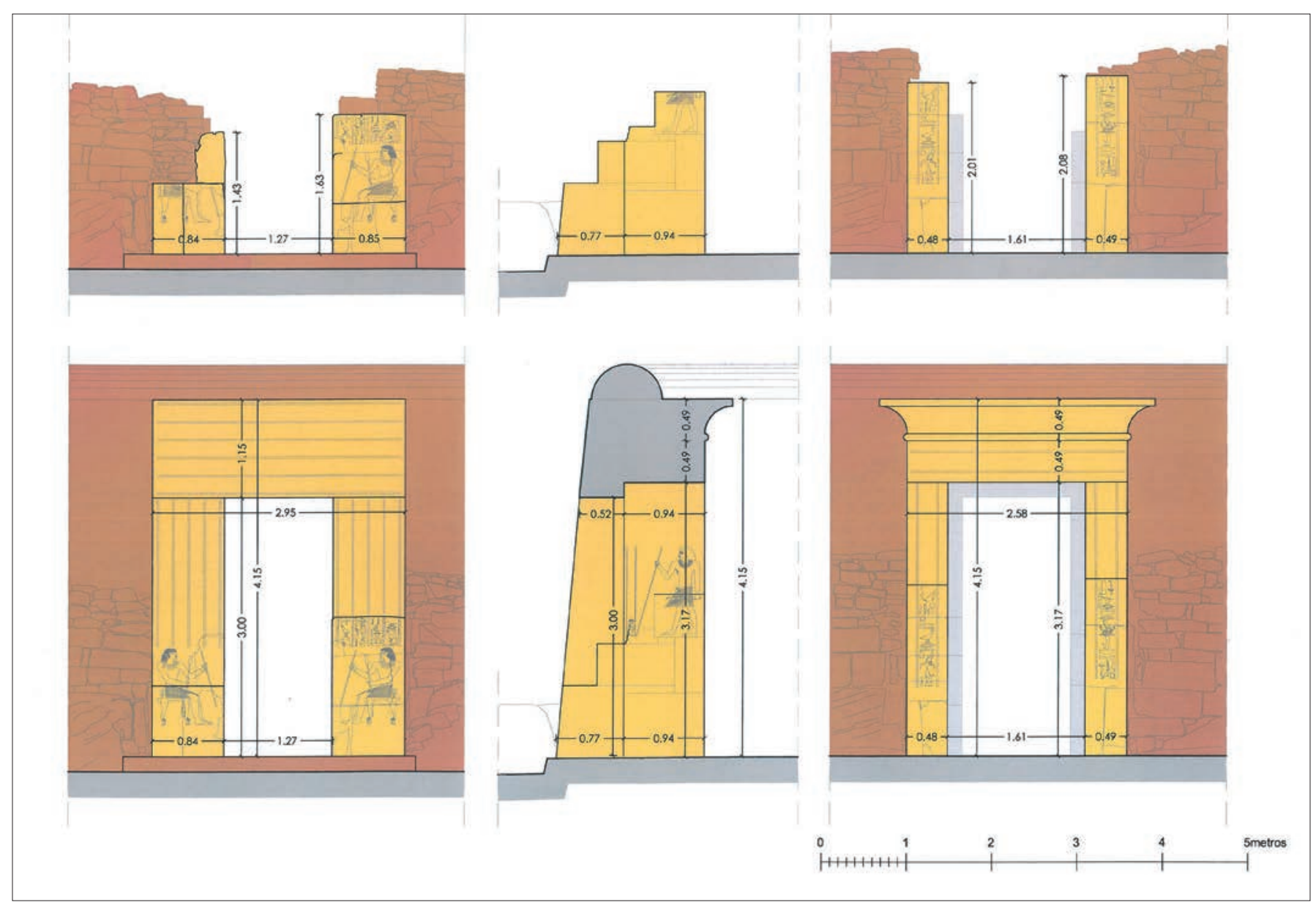

Figura 16. Puerta de acceso al patio exterior del complejo funerario de Sarenput I (QH36). En la parte superior, estado actual; y en la inferior, reconstrucción. 
Probablemente, el marco interior de la puerta contaba con una línea de textos jeroglíficos, que recorría el dintel, ahora desaparecido, desde el centro a derecha e izquierda, de manera simétrica, para descender verticalmente por los dos pilares de la fachada. Teniendo en cuenta el ancho de la columna del texto existente en la base de los pilares, a cada lado del hueco de la puerta, la altura del dintel sería de 0.49 metros, igual al ancho de los pilares, a la que tendríamos que sumar otros 0.49 metros de la altura del bloque terminado con una moldura toro sobre una cornisa caveto.

Por lo tanto, la altura total de la puerta, incluyendo dintel y cornisa de remate, también sería de unos de 4.15 metros, la misma que por el frente que da al exterior del complejo funerario.

En la necrópolis encontramos muchos santuarios tipo naos con este mismo diseño. Por ejemplo, el que se encuentra en el interior de la capilla del complejo funerario QH31 (Sarenput II) (Martínez Hermoso 2017: 280-290, figs. 7.23-7.29), que es el único que fue completamente acabado y decorado.

Y en Lisht (sur), Dieter Arnold propone un diseño similar para la reconstrucción del santuario de la capilla funeraria de la tumba de Ip $/ / /^{4}$ (alto funcionario durante el reinado de Senwosret I), a partir de pequeños fragmentos encontrados entre los escombros, durante la excavación del pozo $\mathrm{n}^{\circ} 17$, en la tumba $\mathrm{C}$ del área sur (2008: 57, pl. 106b), aunque ahora la fachada contaba con dos líneas horizontales de inscripciones en el dintel y otras dos columnas verticales en cada uno de los pilares de la fachada, y estaba rematada por una cornisa caveto.

Además, sobre la utilización de la cornisa caveto, encontramos un ejemplo similar en Lisht, en la capilla norte de la pirámide del $K a$ del complejo funerario de Senwosret I. Esta pequeña capilla fue construida con muros de bloques de piedra caliza, teniendo como pared posterior el muro inclinado de la misma pirámide. El techo fue construido con losas de piedra que apoyaban sobre los muros terminando en todo su perímetro con la habitual cornisa caveto (Arnold 1988: 73, 76-83, figs. 52 b, 99 y 102).

\section{Reconstruccion propuesta por H. W. Müller}

H. W. Müller, propuso la reconstrucción de la puerta de entrada, con una menor altura, y con un diseño basado en ejemplos del Reino Antiguo, como el complejo

\footnotetext{
4 El nombre es Ip[...] porque está destruido.
}

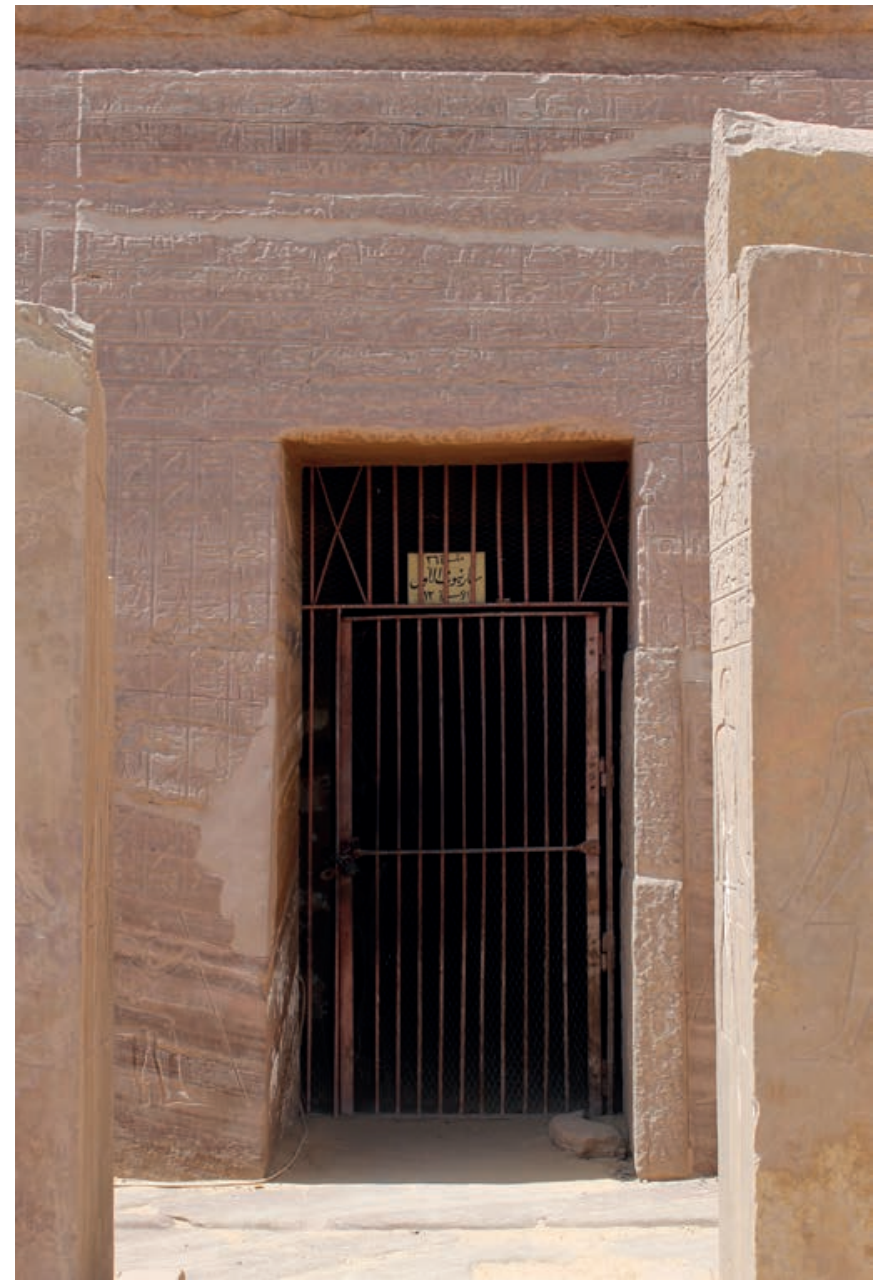

Figura 17. Puerta de entrada a la capilla del complejo funerario de Sarenput I (QH36).

piramidal de Kefrén, en Guiza (Dinastía IV), pero no tuvo en cuenta otros ejemplos de la arquitectura egipcia contemporánea al complejo funerario QH36 que se caracterizan por el empleo de otras soluciones arquitectónicas completamente distintas.

Además, se basa en un fragmento de un bloque de caliza, con perfil redondeado, pero de menores dimensiones que los de arenisca conservados en el patio, que supuestamente fue encontrado en las proximidades del complejo funerario (?), en la ladera de la necrópolis (1940: 17-18).

Sin embargo, tenemos que señalar que, aunque se han encontrado varios fragmentos de piedra caliza, con distintas formas y tamaños, lo más probable es que éstos procedan del desbaste de los bloques de dintel y jambas de la puerta. En realidad, no se ha hallado ningún bloque de piedra caliza completo con la forma redondeada de los bloques de coronación del muro del recinto exterior. 
De hecho, pensamos que esta propuesta no es fiable ni rigurosa con la estructura original existente en este complejo funerario, terminada o no.

\section{CONCLUSIONES}

Mediante el uso de la realidad virtual se pretende mejorar los actuales procesos de investigación, conservación y difusión del importantísimo patrimonio monumental de la necrópolis de Qubbet el-Hawa y, en especial, del complejo funerario QH36 (Sarenput I). Se trata de uno de los escasos ejemplos de arquitectura funeraria privada egipcia durante el Reino Medio que, de manera simplificada, fueron construidos con la forma de templos-tumba de los monarcas de este período (monumento funerario del tipo hipogeo bajo templo, como es el caso del templo funerario de Mentuhotep II en Deir el-Bahari) con escalera ascendente, patio exterior, fachada porticada, capilla funeraria y cámaras subterráneas de enterramiento.

El método de investigación que hemos utilizado para la reconstrucción de los espacios exteriores del complejo funerario QH36 se ha basado en dos niveles de conocimiento:

Por un lado, la parte de la reconstrucción de la fachada porticada y el muro delimitador del patio exterior tiene un alto nivel de fiabilidad y rigurosidad, basado en los elementos arquitectónicos conservados parcialmente y otras evidencias arqueológicas que pueden observarse en el recinto exterior.

Por otro lado, la parte de la reconstrucción de la puerta de piedra caliza de acceso al patio exterior, donde la falta de conservación de algunos de elementos arquitectónicos y de otras evidencias arqueológicas, se suple con otros ejemplos de arquitectura egipcia contemporánea, proponiendo una hipótesis lo más aséptica que permite un grado de certeza riguroso.

Sobre el material que falta de las diversas estructuras del complejo, sobre todo el de las partes exteriores, aunque en principio podría indicar que éste no llegase a ser completamente terminado, no se puede descartar la posibilidad de que fuese saqueado.

Sobre la hipótesis de reconstrucción ideal de la puerta de acceso al patio exterior, de H.W. Müller, creemos que no es ni fiable ni rigurosa con la historia, ya que en lugar de basarse en ejemplos arquitectónicos contemporáneos al complejo funerario QH36, toma otros ejemplos más antiguos en los se empleaban soluciones arquitectónicas muy diferentes.
Y por último, queda en el aire una pregunta interesante, ¿puede considerarse que la reconstrucción ideal del exterior del complejo funerario QH36 sea el diseño arquitectónico inicial que se adopto durante la Dinastía XII para los exteriores de los complejos funerarios en Qubbet el-Hawa? y, en ese caso, ¿podría trasladarse esta solución arquitectónica "tipo" al resto de los exteriores inacabados de los complejos funerarios construidos durante este período cuyas obras fueron abandonadas antes de finalizarlas, entre otros motivos, debido a la muerte de sus propietarios?

Nunca podremos saberlo con certeza.

\section{BIBLIOGRAFÍA}

Arnold, D. 1979: The Temple of the Mentuhotep at Deir el-Bahari, from the notes of Herbert Winlock. MMA. Egyptian Expedition 21, New York.

Arnold, D. 1988: The pyramid of Senwosret I. The Metropolitan Museum of Art, New York.

Arnold, D. 1991: Building in Egypt. Pharaonic Stone Masonry. Oxford University Press, New York.

Arnold, D. 1992: The Pyramid Complex of Senwosret I. Oxford University Press, New York.

Arnold, D. 2008: Middle Kingdom Tomb Architecture at Lisht. The Metropolitan Museum of Art, New York.

Badawy, A. 1966: A History of Egyptian Architecture. The First Intermediate Period, the Middle Kingdom, and the Second Intermediate Period. University of California Press, Los Ángeles.

Bisson de la Roque, F. 1937: “Töd (1934 a 1936)”, IFAO, 17, pp. 6-33.

Borchardt, L. 1938: “Aegyptische Tempel mit Umgang”, Beiträge zur ägyptischen Bauforschung und Altertumskunde, 2, pp. 56-57.

Budge, W. 1887: "Excavations made at Aswan by Major-General Sir F. Grenfell during the years 1885 and 1886", PSBA, X, pp. 4-40.

Carta de Sevilla 2012: Principles of Seville. International Principles of Virtual Archaeology. http://www.arqueologiavirtual.com [consultado el 31/08/2017].

Chevrier, H. 1938: "Reconstruction d'un Temple de Sesostris Ier a Karnak", Archiv fur Ägyptische Archaologie, 1, pp. 8-9.

Clarke, S. y Engelbach, R. 1990: Ancient Egyptian Construction and Architecture. Dover Publications, Inc., Nueva York.

Davies, N. de G. 1913: Five Theban Tombs. Egypt Exploration Fund, London.

Davies, N. de G. y Gardiner, H. A. 1920: The tomb of Antefoker, Vizir of Sesostris I and of his wife Senet. The Theban Tombs series, second memoir, EES, London: G. Allen \& Unwin.

De Morgan, J. et al. 1894: Catalogue des monuments et inscriptions de $l$ '̇̀gypte Antique. Haute Égypte. Tome Premier: de la frontière de Nubie â Kom Ombos. Adolphe Holzhausen, Vienne.

Denard, H. (ed.) 2009: "The London Charter for the computer-based visualisation of cultural heritage", King's College London, february, pp. 1-13.

El-Khadragy, M. 2007: "The Shrine of the Rock cut Chapel of Djefaihapi I at Asyut", Göttinger Miszellen, 212, pp. 41-6.

García González, L. M. 2011: Sarenput I: Estudio Histórico de un Nomarca de Ta-Seti a principios de la Dinastía XII. Trabajo Fin de Máster. Universidad de Jaén.

Gardiner, A. H. 1908: "Inscriptions from the tomb of Si-renpowet I, prince of Elephantine", Z̈̈S, 45, pp. 123-140.

Hornung, E., Krauss, R. y Warburton, D. A. 2006: Ancient Egyptian Chronology. Brill, Leiden, Boston.

Kaiser, W. 1988: "Zur Rekonstruction des Satettemples der 12. Dynastie", MDAIK, 44, pp. 152-154. 
Lacau, P. y Chevrier, H. 1956: Une chapelle de Sésostris Ier à Karnak. Le Caire. Martín Talaverano, R. 2014: "Documentación gráfica de edificios históricos: principios, aplicaciones y perspectivas", Arqueología de la Arquitectura, 11: e011. https://doi.org/10.3989/arq.arqt.2014.014

Martínez Hermoso, F. 2012: La tumba de Sarenput I. Arquitectura y Representación Gráfica. Trabajo de Fin de Máster. Universidad de Córdoba.

Martínez Hermoso, J. A. 2015: “Arquitectura funeraria durante el Reino Medio en Qubbet el-Hawa. El complejo funerario de Sarenput II", Actas del V Congreso Ibérico de Egiptología. Cuenca 9-12 marzo 2015, Colección Estudios 157. Universidad de Castilla la Mancha, Cuenca.

Martínez Hermoso, J. A. et al. 2015: "Geometry and Proportions in the Funeral Chapel of Sarenput II", Nexus Network Journal. Architecture and Mathematics, 17, 1, pp. 287-309. https://doi.org/10.1007/s00004-014-0218-4

Martínez Hermoso, J. A. 2017: Representación Gráfica y Diseño de la tumba de Sarenput II (QH31). Arquitectura funeraria de la necrópolis de Qubbet el-Hawa. Colección Tesis Doctorales UCO del Repositorio Helvia de la Universidad de Córdoba. UCOPress. http://hdl.handle.net/10396/14783
Müller, H.W. 1940: Die Felsengräber der Fürsten von Elephantine aus der Zeit des Mittleren Reiches. Verlag J. J. Augustin, Glückstadt-Hamburg-New York. Naville, E. 1910: The XIth Dynasty Temple at Deir el-Bahari. The Egypt Exploration Fund, London.

Petrie, F. 1930: Anteopolis. The tombs of Qau. British School of Archaeology in Egypt University College, London.

Sethe, K. 1935: "Historisch-biographische Urkunden des Mittleren Reiches I". Urkunden des ägyptischen Altertums, (Urk) VII, pp. 4-5.

Soliman, R. 2009: Old and Middle Kingdom Theban Tombs. Golden House Publications, London.

Steckeweh, H. 1936: Die Fürstengräber von Qaw. Veröffentlichungen der Ernst von Sieglin-Expedition, Leipzig.

Winlock, H. E. 1942: Excavations at Deir el-Bahri 1911-1913. Macmillan, New York.

Winlock, H. E. 1943: "The Eleventh Egyptian Dynasty", Journal of Near Eastern Studies, 2/4, pp. 249-283.

Winlock, H. E. 1955: Models of daily in Ancient Egypt from the tomb of Meketre at Thebes. The Metropolitan Museum of Art, New York. 